\title{
Presentaciones en cartel
}

\section{REDES Y DESARROLLO EN SALUD PÚBLICA}

\section{Serorreacciones en bancos de sangre, Colombia, 2000 a 2010}

María Isabel Bermúdez, Mauricio Beltrán

Coordinación Red Nacional Bancos de Sangre, Instituto Nacional de Salud, Bogotá, D.C., Colombia

mbermudez@ins.gov.co

Introducción. En Colombia contamos con una normativa para la red de bancos de sangre, en la que se establece la obligatoriedad de las pruebas de tamización a favor de la seguridad de los productos sanguíneos obtenidos

Objetivo. Evaluar el comportamiento de las reacciones para los diferentes marcadores infecciosos y su relación con los tipos de donantes aceptados

Materiales y métodos. Se realizó un estudio descriptivo retrospectivo a partir del sistema de información de la Red Nacional de Bancos de Sangre, recopilando información entre los años 2000 y 2010.

Resultados. Por cada donante repetitivo que presentó reactividad para algún marcador infeccioso, tres personas -donantes por primera vez- presentaron el mismo comportamiento. Se observó que los porcentajes de donantes de primera vez y reposición tienen una relación directamente proporcional respecto a las reacciones para marcadores infecciosos. Las tendencias de las reactividades paraalgunos marcadores presentaron un comportamiento heterogéneo como ocurre con VIH, VHC y sífilis.

Conclusión. Dada la relación observada entre los donantes de primera vez y las serorreacciones, se requiere incrementar la captación de sangre a partir de donantes repetitivos, con el fin de disminuir las reacciones y aumentar la disponibilidad de sangre segura en Colombia.

Palabras clave: bancos de sangre, tamización, reactividad

\section{Referencias}

1. Instituto Nacional de Salud. Informe OPS, 2010.
2. Ministerio de la Protección Social. Decreto 1571 de 1993: "Sangre segura para todos".

3. Prevalencia en donantes de sangre, Colombia 2007-2009. Inf Quinc Epidemiol Nac. 2010.

4. Algoritmo para pruebas infecciosas para banco de sangre. Boletín técnico Red de Sangre.

\section{Donación de sangre, 2005-2010}

Maritza Berrío, Mauricio Beltrán, Magda Juliana Rodríguez

Coordinación Red nacional de Bancos de sangre y servicios de transfusión, Instituto Nacional de Salud, Bogotá, D.C., Colombia

mbeltrand@ins.gov.co

Introducción. La promoción de la donación de sangre es el primer eslabón en la cadena de la seguridad en las transfusiones. En Colombia, la red de sangre ha trabajado para incrementar los donantes voluntarios habituales, considerados los más seguros, a diferencia de los donantes de primera vez y los de reposición.

Objetivo. Analizar el incremento de la donación voluntaria y habitual de sangre comparado con la reacción a los cinco marcadores infecciosos de tamización obligatoria.

Materiales y métodos. Se realizó un estudio descriptivo empleando la información de la red de bancos de sangre de 2005 a 2010. Las variables evaluadas fueron: número de unidades captadas, donantes habituales, donantes de reposición y donantes voluntarios.

Resultados. Entre 2005 y 2010, se obtuvieron 3'661.837 unidades, en las que el índice de donación por mil habitantes cambió de 12,3 en 2005 a 15,2 en 2010. Los departamentos con mayor número de donantes habituales fueron: Cadas $(59,25 \%)$, Putumayo (34,76\%), Arauca (33,42\%), Boyacá $(27,16 \%)$ y Risaralda $(23,51 \%)$. El porcentaje de unidades reactivas a marcadores infecciosos fue más bajo en Boyacá (1,65\%), Nariño $(1,95$ $\%)$, Cauca (1,96 \%), Caldas (2,16\%) y Córdoba $(2,28 \%)$. Para Boyacá y Caldas se observó un comportamiento inversamente proporcional entre 
donación voluntaria habitual y reacciones, lo cual está acorde con las metas nacionales de calidad y seguridad sanguínea.

Conclusión. Es necesario fortalecer la promoción de la donación para generar cultura de donación habitual y, de esta manera, fortalecer la seguridad de las transfusiones.

Palabras clave: donantes de sangre, Colombia, seguridad de las transfusiones

\section{Referencias}

1. Epstein JS. Alternative strategies in assuring blood safety: an overview. Biologicals. 2003;38:31-5

2. Behrend $\mathrm{M}$, Beltrán $\mathrm{M}$, Restrepo $\mathrm{M}$, Kroeger $\mathrm{A}$. Control de la enfermedad de Chagas en bancos de sangre de Colombia. Biomédica. 2002;22:39-45.

3. Rodríguez MJ. la promoción de la donación voluntaria y habitual de sangre como impacto en la seguridad transfusional, Colombia, 2010.

4. Boletín informativo: "Salud transfusional". Red Nacional de Sangre, Instituto Nacional de Salud. 2011;5:1-5.

\section{Hemovigilancia: análisis de casos de reacciones adversas a las transfusiones, Colombia, 2010}

Óscar Peñuela, Mauricio Beltrán

Coordinación Nacional Red de Sangre, Subdirección Red Nacional de Laboratorios, Instituto Nacional de Salud, Bogotá, D.C., Colombia.

mbeltrand@ins.gov.co

Introducción. Los sistemas de hemovigilancia permiten conocer el tipo y la frecuencia de las reacciones adversas a las transfusiones, detectar sus causas y generar retroalimentación para prevenir nuevos casos; además, permite garantizar la trazabilidad del sistema, impulsa la implementación de nuevas tecnologías y es una herramienta clave de educación en la formación del personal médico y asistencial en la utilización terapéutica correcta de los productos sanguíneos, en la seguridad del paciente y en el desarrollo de políticas estatales de salud.

Objetivo. Describir la frecuencia de las reacciones adversas a las transfusiones en la red de sangre durante el año 2010.

Materiales y métodos. Se realizó un estudio descriptivo empleando como fuente de información el subsistema de vigilancia (hemovigilancia) de la red nacional de sangre. Las variables de interés fueron: los tipos de componentes sanguíneos, las reacciones adversas a las transfusiones y la imputabilidad según las definiciones del manual nacional de hemovigilancia.

Resultados. En2010, se notificaronal sistema1.198 casos de reacciones adversas a transfusiones, en 900.460 unidades de componentes transfundidos, que equivale a una tasa de 1,33 por 1.000 unidades. El $92,4 \%$ fueron leves, $5,43 \%$ moderadas y $2 \%$ seria. Hubo dos casos sospechosos de muerte asociada a la transfusión $(0,17 \%)$, pero sólo un caso tuvo imputabilidad definitiva (grado 3 ), y el otro fue excluido (grado 0 ).

Conclusión. La mayoría de los casos de reacciones adversas a las transfusiones fueron agudas no infecciosas; las tardías no infecciosas y las infecciones transmitidas por transfusión fueron la minoría dada la dificultad para establecer la asociación etiológica con la transfusión. Este es el primer informe nacional de casos de reacciones adversas a las transfusiones del sistema de hemovigilancia.

Palabras clave: hemovigilancia, reacción adversa, transfusión.

\section{Referencias}

1. Heddl NM, Kelton JG. Febrile nonhemolytic transfusion reactions. En: Popovsky MA, editor. Transfusion reactions. Second edition. Bethesda, MD: AABB Press; 2001. p. 4582.

2. Palfi M, Berg S, Ernerudh J, et al. A randomized controlled trial of transfusion related acute injury: Is plasma from multiparous blood donors dangerous? Transfusion. 2001;41:317-22

3. Peñuela O, Beltrán M, Rebollo S. Manual de hemovigilancia. Bogotá: Instituto Nacional de Salud; 2010.

\section{Prevalencia de VIH en donantes de sangre, Colombia, 2007-2009}

Mauricio Beltrán, Maritza Berrío-Pérez

Coordinación Nacional Red de Sangre, Instituto Nacional de Salud, Bogotá, D.C., Colombia

mberrio@ins.gov.co

Publicado en: Inf Quinc Epidem Nac. 2010;15(24):369-71.

Introducción. La prevalencia de $\mathrm{VIH}$ en donantes es usada como indicador de seguridad de la transfusión, dado que permite evidenciar la calidad de la selección de donantes y distinguir entre los tipos de donantes: voluntario de primera vez, de reposición o voluntario habitual o repetitivo. 
Objetivo. Estimar la prevalencia de $\mathrm{VIH}$ en donantes de sangre con base en la información de la vigilancia de la red de bancos de sangre.

Materiales y métodos. Se realizó un estudio descriptivo, empleando el subsistema de vigilancia de la red nacional de bancos de sangre como fuente de información. Entre las variables de interés evaluadas se encuentran el tipo de donante, las unidades de sangre obtenidas, las unidades reactivas a anticuerpos contra $\mathrm{VIH}^{1} 12$, los donantes confirmados, los resultados positivos para VIH. Para el análisis de la información se tuvieron en cuenta los porcentajes de reacción en la tamización, los resultados positivos por Western blot y la tasa de positivos de $\mathrm{VIH}^{1} 1 / 2$ por 100.000 donaciones por departamento.

Resultados. Durante los tres años, todos los bancos del país recolectaron 1'889.250 unidades. Catorce por ciento fueron donadas por donantes voluntarios y habituales. Todas fueron analizadas para anticuerpos contra $\mathrm{VIH}^{1} / 2$, y 7.241 se hallaron que eran reactivas $(0,38 \%)$. Los laboratorios de referencia recibieron para confirmación 4.404 $(60,82 \%)$, y 1.165 se reportaron como positivas. La tasa promedio nacional ajustada de prevalencia para VIH en donantes fue de 102 por 100.000, 13 departamentos presentaron tasas superiores.

Conclusión. En Colombia, la prevalencia de VIH en donantes de sangre es alta comparada con los países con mayor número de donantes habituales.

Palabras clave: banco de sangre, donantes, Colombia, VIH.

\section{Referencias}

1. ONUSIDA. AIDS epidemic update 2009: November 2009 Disponible en: http://data.unaids.org/pub/Report/2009/ JC1700_Epi_Update_2009_en.pdf.

2. Perkins HA, Busch MP. Transfusion-associated infections: 50 years of relentless challenges and remarkable progress. Transfusion. 2010;55:2080-99.

3. García R. AIDS: status in the world and in Colombia 20 years later. Biomédica. 2003;23:247-51.

\section{Análisis conceptual del estrés en las teorías biológica, ambiental y transaccional en artículos colombianos}

Máncel Martínez R.

Servicio de Epidemiología, programa FETP de entrenamiento en Epidemiología de Campo, Subdirección de Vigilancia y Control en Salud Pública, Instituto Nacional de Salud, Bogotá, D.C., Colombia.

mmancel@yahoo.com.mx

Introducción. Se explora el concepto del estrés y las prácticas en salud que se derivan de su uso, en tres teorías diferentes (biológica, ambiental y transaccional) tomando herramientas del método de análisis propuesto por Wittgenstein, para ubicar confusiones conceptuales y aclarar teóricamente dicho concepto. Estas confusiones tienen repercusiones nocivas para la salud.

Objetivo. Describir el uso en artículos colombianos del concepto estrés en las teorías biológica, ambiental y transaccional, para aclarar confusiones conceptuales.

Materiales y métodos. Estudio cualitativo. Análisis conceptual a partir de la gramática de Wittgenstein. Se escogió un grupo de artículos colombianos de investigaciones sobre el estrés en las teorías biológica, ambiental y transaccional. Se analizaron por separado los artículos de cada teoría, estableciendo sus principales confusiones conceptuales, examinando la coherencia interna en la definición del concepto, su medición e intervención. Finalmente, se compararon las teorías entre sí a partir de los artículos.

Resultados. Se identificaron confusiones conceptuales en las tres teorías y entre ellas. Las principales están relacionadas con las categorías de confusiones en juegos del lenguaje, la primacía de lo general sobre lo particular, el planteamiento de definicionesuniversalesyanalogías desafortunadas. El principal problema identificado fue la falta de coherencia entre la teoría y los tratamientos.

Conclusión. Se presentaron frecuentes confusiones en el uso del concepto estrés en las tres teorías analizadas; el empleo del concepto es diverso hasta el punto de diluirse o no tener sentido en algunos casos. El método de aclaración conceptual de Wittgestein es un método crítico de análisis del lenguaje que permitió ubicar confusiones, aclarar significados, alcances y relaciones de similitud y diferencia entre las teorías. Las confusiones conceptuales en torno al estrés generan graves repercusiones para la salud, como la ambigüedad en el uso del concepto que dificulta los diagnósticos, y se confunden los tratamientos de una teoría con los de otra lo que hace que no haya coherencia entre teoría y aplicación, y dificulta la evaluación de resultados en los tratamientos. 


\section{Referencias}

1. Lazarus RS. From psychological stress to the emotions: a history of changing outlooks. Annu Rev Psychol. 1993;44:121.

2. Guerrero J. Los roles no laborales y el estrés en el trabajo. Revista Colombiana de Psicología. 2003;12:73-84.

3. Montaño JI, Dossman X, Herrera JA. Helicobacter pylori $y$ estrés psicosocial en pacientes con gastritis crónica. Colombia Médica. 2006;37:39-44.

\section{Panorama de la intoxicación aguda por sustancias psicoactivas en Colombia, 2007-2010}

José Urrego, John Jairo Abella, Manuel Salgado

Grupo de Factores de Riesgo Ambiental, Subdirección de Vigilancia y Control en Salud Pública, Instituto Nacional de Salud, Bogotá, D.C., Colombia

jurrego@ins.gov.co

Introducción. La creciente utilización de sustancias psicoactivas, principalmente a edades cada vez menores, ocasiona un serio problema de salud pública. El desconocimiento de sus consecuencias sobre la salud, el uso indiscriminado, la tendencia de consumo y el uso delictivo son algunos de los factores que conllevan riesgo de intoxicación aguda debido al consumo de sustancias psicoactivas. Hasta el momento se tiene información de diversos autores sobre el consumo realizado, pero no se conoce información sobre el comportamiento de los cuadros de intoxicación aguda generados por estas sustancias en el país. Por tal razón, este trabajo pretendió brindar información -hasta el momento no existente- que permita delinear políticas de salud pública en el contexto colombiano.

Objetivo. Evaluar la información generada por la notificación de casos de intoxicación por sustancias psicoactivas, de acuerdo con los procesos establecidos para la notificación al Sivigila mediante la generación de un panorama de la intoxicación por sustancias psicoactivas de 2007 al 2010.

Materiales y métodos. Se llevó a cabo una revisión retrospectiva de la notificación de intoxicación aguda debida a sustancias psicoactivas proveniente de las UPGD del país a través del Sivigila durante los años 2007 a 2010, con el fin de generar información oportuna, válida y confiable para orientar la elaboración de un protocolo para vigilancia de la intoxicación aguda por este tipo de sustancias en el país. Se desarrolló un estudio descriptivo retrospectivo mediante la determinación de variables epidemiológicas descriptivas (persona, tiempo y lugar), sobre el comportamiento de la intoxicación aguda por sustancias psicoactivas (etanol, tetrahidrocanabinoles, cocaína y derivados, drogas de síntesis, alucinógenos, derivados del opio, benzodiacepinas, etc. Se partió de la fuente de información contenida en el Sivigila.

Resultados. El $75,61 \%$ de los casos de intoxicación por sustancias psicoactivas se produjo por ingestión, lo cual concuerda con el hecho de que, aproximadamente el 40,41\% de los eventos de intoxicación notificados son resultado del consumo de etanol, principalmente por ingestión; a su vez; el $31,67 \%$ de los eventos de intoxicación por sustancias psicoactivasnotificadossondebidosaintencionalidad delictiva. Se observa que, aproximadamente, el $36,87 \%$ de las hospitalizaciones se generaron por la atención de este tipo de evento. La sustancia psicoactiva de mayor incidencia de intoxicación es el etanol $(40,41 \%)$ seguido por la escopolamina $(24,49 \%)$, las mezclas de sustancias $(11,45 \%)$ y la cocaína y sus derivados (9,45\%). El grupo de edad con mayor incidencia de intoxicación aguda está comprendido entre los 15 y los 24 años con el 40,67 $\%$ de la notificación para este evento en particular.

Conclusión. La información generada a partir del presente estudio permite establecer el comportamiento de la intoxicación aguda generada por sustancias psicoactivas, hasta el momento desconocida en el país.

Palabras clave: intoxicaciones, sustancias psicoactivas, salud mental.

\section{Referencias}

1. Doull CD. Toxicology. New York: Mc Graw Hill; 2008.

2. Goldfrang LR, Lewin NA. Toxicological. 1994.

3. Merck \& Co. The Merck Index. Boston: Merck Publishing; 2009.

\section{Guía para el desarrollo de la vigilancia comunitaria en albergues}

Heidy García, Eddier Martínez, Andrea Rodríguez

Grupo de Análisis de Situación de Salud, Subdirección de Vigilancia y Control en Salud Pública, Instituto Nacional de Salud, Bogotá, D.C., Colombia.

hgarcia@ins.gov.co

Introducción. La actual ola invernal que afecta el país ha llevado a adoptar medidas para proteger a la población de las diversas amenazas a las que se enfrenta; una de las medidas más importantes 
es el alojamiento de la población afectada en albergues.

Objetivo. Integrar a la comunidad en los procesos de apropiación e identificación de factores que pueden afectar su salud y la de la comunidad albergada.

Materiales y métodos. La implementación de un proceso de vigilancia comunitaria de signos y síntomas busca la identificación de enfermos en su etapa inicial, lo cual permite detectar brotes y situaciones de riesgo, para una intervención oportuna que permita tomar medidas de control para la mitigación del impacto de estas situaciones en la comunidad.

Resultados. La propuesta de vigilancia comunitaria busca generar un líder comunitario en cada uno de los albergues, quien realizará la vigilancia diaria de signos y síntomas y actuará como nodo articulador con la persona asignada a nivel municipal y que recopila toda la información de los albergues de su municipio, activa las alertas respectivas en caso de que se requiera, sistematiza la información y sirve como nodo articulador con una persona asignada en el nivel departamental, en donde se tabula y analiza con el fin de servir de insumo para la toma de decisiones en cada una de las salas departamentales de crisis.

Conclusión. Este proceso se encuentra en construcción y pasará a pruebas piloto durante este año, antes de ser implementado en las entidades territoriales. Se espera que esta guía de vigilancia se implemente para recopilar información en los alojamientos temporales y refugios que se generen a partir de cualquier desastre que suceda en nuestro país.

Palabras clave: vigilancia epidemiológica, comunidad, albergues, ola invernal.

\section{Referencias}

1. OPS/OMS, SDS. Vigilancia epidemiológica en situación de emergencias y desastres. Honduras: OPS/OMS; 2004.

2. OPS/OMS. Vigilancia epidemiológica sanitaria en situaciones de desastre. Washington, D.C.: OPS; 2002.

3. Cruz Roja Colombiana. Manual nacional para el manejo de albergues temporales, 2008. Disponible en: http://www. cruzrojacolombiana.org/publicaciones/pdf/manual_final_ albergues_temporales_1912011_035711.pdf.

4. CDC. Community Assessment for Public Health Emergency Response (CASPER) toolkit. Atlanta: CDC; 2009.

5. Tognoni G. Manual de epidemiologia comunitaria. CECOMET; 1997.
Evaluación de las acciones de detección temprana de alteraciones del adulto de 45 y más años, pertenecientes al régimen subsidiado y pobres no asegurados, Villavicencio, Colombia, 2009-2010

Gladys Espinosa, Franklin Prieto, Adriana Madroñero, Betsy Bello, Claudia Roncancio, Daniel Alejandro Buitrago, Ivonne Natalia Solarte, Luis Fernando Fuertes, María Cristina Romero, María Magdalena Santos, María Natalia Muñoz, Marlene de Jesús Guerra, Martha Cecilia Santos, Nery Astrid Pabón, Nohora Rodríguez, Oneida Castañeda, Pablo Enrique Chaparro, Ruby Trejo, Sandra Misnaza, Sara García, Teresa Moreno

Programa de Entrenamiento en Epidemiología de Campo; Subdirección de Vigilancia y Control en Salud Pública, Instituto Nacional de Salud, Bogotá, D.C., Colombia.

isolarte@ins.gov.co

Presentado en: Conferencia, Instituto Nacional de Salud, 24 de junio de 2011

Introducción. Colombia incluyó en el 2000 dentro de sus lineamientos de prevención para la atención primaria en salud, las acciones de detección temprana de condiciones crónicas de adultos. Sin embargo, el cumplimiento de estas actividades aún no se ha evaluado.

Objetivo. Evaluar el cumplimiento de las acciones de detección temprana en el adulto mayor de 45 y más años, contempladas en la guía nacional, Villavicencio, 2009-2010.

Materiales y métodos. Se realizó un estudio transversal a partir de los datos rutinarios del sistema de salud. Las historias clínicas se evaluaron según el cumplimiento de los estándares de la guía, mediante revisión y lista de chequeo de 179 historias clínicas en 11 unidades de salud. Cada revisión fue criticada por pares. Se recolectó información sobre antecedentes, valoración clínica y de laboratorio, diagnóstico e intervenciones.

Resultados. Hubo registro completo de antecedentes y valoración clínica. A $93 \%$ le solicitaron laboratorios estándar y en $36,7 \%$ se registró el resultado. La información recolectada en la historia clínica se utilizó para orientar conductas en el $50,8 \%$. El $78 \%$ con algún antecedente y el 61 $\%$ con factores de riesgo, ambos asintomáticos, fueron remitidos a control en cinco años. El $24 \%$ sintomático y con factores de riesgo fue canalizado para confirmación diagnóstica de evento crónico. 
Conclusión. Existe un registro completo de la información aportada por la persona y cumplimiento parcial del uso de pruebas diagnósticas. La información no se utiliza para definir conductas, por lo cual, se hace necesario el entrenamiento médico en la interpretación y uso de la información registrada para generar planes de atención individual.

Palabras clave: enfermedades crónicas, detección temprana, Resolución 412.

\section{Referencias:}

1. República de Colombia. Ministerio de Salud, Dirección General de Promoción y Prevención. Norma técnica para la detección de las alteraciones del adulto.

2. República de Colombia. Ministerio de la Protección Social. Resolución por la cual se establecen las actividades, procedimientos e intervenciones de demanda inducida y obligatorio cumplimiento y se adoptan las normas técnicas y guías de atención para el desarrollo de las acciones de protección específica y detección temprana y la atención de enfermedades de interés en salud pública. Resolución 412 de 2000 (febrero 25).

3. República de Colombia. Ministerio de la Protección Social. Guía para la prevención de la enfermedad crónica y mantenimiento de la salud en el individuo sano mayor de 45 años.

\section{Estudio costo-enfermedad del síndrome de dificultad respiratoria en el recién nacido en una institución prestadora de servicios de salud de Bogotá}

José Urrego ${ }^{1}$, Jorge Díaz ${ }^{2}$

1 Grupo de Factores de Riesgo Ambiental, Subdirección de Vigilancia y Control en Salud Pública, Instituto Nacional de Salud, Bogotá, D.C., Colombia

2 Departamento de Farmacia, Facultad de Ciencias, Universidad Nacional de Colombia, Bogotá, D.C., Colombia

jurrego@ins.gov.co

Introducción. La escasez de información basada en estudios realizados mediante metodología costo-enfermedad en Colombia, constituye un problema prioritario para la organización de los sistemas asistenciales de salud. Esta problemática se ve condicionada, fundamentalmente, por dos circunstancias: el incremento de los costos de los insumos para la salud y los pocos datos que existen para identificar los montos económicos que alcanza la producción de un servicio en la atención de una enfermedad en particular, según los insumos y las funciones de producción que se requieren.
La realización de un estudio costo-enfermedad en el síndrome de dificultad respiratoria del recién nacido permite originar información necesaria para el desarrollo de evaluaciones económicas de tecnología sanitaria que permitan brindar una atención enmarcada dentro del concepto de la economía del bienestar.

Objetivo. Evaluar la carga económica originada por el síndrome de dificultad respiratoria del recién nacido en una cohorte de pacientes internados en la unidad de cuidados intensivos neonatales de una institución prestadora de servicios de salud (IPS) de Bogotá.

Materiales y métodos. Se evaluó la carga económica originada por el síndrome de dificultad respiratoria del recién nacido en una cohorte de pacientes internados en la unidad de cuidados intensivos neonatales de una IPS de Bogotá. Se aplicó la metodología de un estudio costoenfermedad, bajo un enfoque de "abajo hacia arriba" y basado en prevalencia en el que se determinaron costos directos, indirectos e intangibles; lo anterior permitió establecer una fuente de información -hasta ahora no existente en el país- para realización de estudios de evaluación económica de tecnología sanitaria.

Resultados. Se identificaron las variables para costo directo, indirecto e intangible en recién nacidos con síndrome de dificultad respiratoria que son hospitalizados en la unidad de cuidados intensivos neonatales. Las variables de las que depende el costo directo fueron calculadas mediante un modelo de regresión lineal múltiple mediante la selección de variables de la metodología stepwise las cuales fueron: estancia, medicamentos, elementos médicos, procedimientos diagnósticos, exámenes especiales, banco de sangre, procedimientos, peso, tiempo de hospitalización y edad de gestación. Para los costos indirectos, la variable contemplada fue la muerte del recién nacido a causa de su enfermedad. En este caso en particular se calcularon los años de vida productiva potencialmente perdidos (AVPPP), los cuales se determinaron mediante el método del capital humano. A partir de este método se obtuvieron los costos indirectos para dos casos de fallecimiento por dicha enfermedad dentro de la cohorte objeto de estudio. Para la obtención de los costos intangibles se preguntó al entrevistado mediante una encuesta estructurada previamente validada, por la disponibilidad de pagar para disminuir la ansiedad, nerviosismo o tensión a causa de la 
hospitalización en la unidad de cuidados intensivos del recién nacido en el tratamiento del síndrome de dificultad respiratoria.

Conclusión. Se obtuvo información innovadora en metodología de abordaje en Colombia para estudios de costo-enfermedad en recién nacidos, y para el síndrome de dificultad respiratoria del recién nacido se obtuvo información de costos directos, indirectos e intangibles hasta ahora no discriminados que servirán como fuente de información para futuras evaluaciones de tecnología sanitaria en esta enfermedad y población particular.

Palabras clave: estudio costo-enfermedad, síndrome de dificultad respiratoria, recién nacidos, gestión de la enfermedad.

\section{Referencias}

1. Akobundu E, Ju J, Blatt L, Mullins CD. Cost-of-illness studies: a review of current methods. Pharmacoeconomics. 2006;24:869-90.

2. Johannesson M, Karlsson G. New approach for estimating indirect costs of disease. J Health Econ. 1996;249-55.

3. Meerding WJ, Polder JJ, Bonneux L, van der Maas PJ. A cross-national perspective on cost of illness - A comparison of studies from the Netherlands, Australia, Canada, Germany, United Kingdom and Sweden. Eur J Health Econ. 2005;6:223-32. 


\section{ENFERMEDADES CRÓNICAS}

\section{Expresión diferencial del gen BCL2 en células de melanoma proliferantes $y$ sometidas a supresión de crecimiento tumoral}

María Luz Gunturiz, Héctor Javier Ardila, Luis Alberto Gómez

Grupo de Fisiología Molecular, Subdirección de Investigación, Instituto Nacional de Salud, Bogotá, D.C., Colombia

Igomez@ins.gov.co

Introducción. El melanoma maligno es un cáncer muy metastásico cuyo mal pronóstico clínico es, en parte, causa de la resistencia a la apoptosis. La homeostasis entre la supervivencia y la muerte celular son controlados por genes antiapoptóticos y propapoptóticos. BCL2 es un protooncogén cuya función principal es bloquear la apoptosis; su expresión ha sido reportada en carcinomas de pulmón y de próstata y en neoplasmas melanocíticos de piel, entre otros, por lo cual es relevante estudiar su papel en condiciones de supresión y proliferación celular.

Objetivo. Evaluar la expresión de BCL2 en células de melanoma B16 y A375 proliferantes y sometidas a supresión de crecimiento tumoral inducida por la 5-bromo-2-desoxiuridina (BrdU).

Materiales y métodos. A partir de $10^{5}$ células B16 y A375 proliferantes y sometidas a tratamiento con $\operatorname{BrdU}(2,5 \mu \mathrm{g} / \mathrm{ml})$, durante 72 horas, se realizó la extracción del ARN y de las síntesis de cADN para evaluar la expresión relativa del mARN de $B C L 2$ mediante PCR en tiempo real, empleando a GAPDH como gen de normalización.

Resultados. Se confirmó que la exposición de las células de melanoma a BrdU $(2,5 \mu \mathrm{g} / \mathrm{ml})$ durante 72 horas promovió la inhibición del crecimiento ( 50\%, t de Student, $p \leq 0,001)$, así como la disminución en la cantidad de melanina en B16 (1,2 Vs. 0,4 mg/106 células). El análisis de expresión de mARN de BCL2 mostró que en células B16 y A375 proliferantes, su expresión es 1 a 2 veces más alta que en las células sometidas a tratamiento con BrdU.

Conclusión. La sobreexpresión del gen antiapoptótico BCL2 en células de melanoma B16 y A375 podría conferir ventaja de proliferación en comparación con las células expuestas a la BrdU. Los resultados permiten sugerir que la expresión del gen BCL2 podría estar implicada en el mecanismo de supresión del crecimiento tumoral inducido por la BrdU, un análogo de la timina.

Palabras clave: melanoma, BCL2, apoptosis, bromodeoxiuridina, expresión diferencial.

\section{Referencias}

1. Kim R, Emi M, Tanabe K. The role of apoptosis in cancer cell survival and therapeutic outcome. Cancer Biol Ther. 2006;5:1429-42.

2. Su DM, Zhang Q, Wang X. Two types of human malignant melanoma cell lines revealed by expression patterns of mitochondrial and survival-apoptosis genes: implications for malignant melanoma therapy. Mol Cancer Ther. 2009;8:1292-304.

3. Furusato E, Hidayat A, Man YG, Auerbach A, Furusato B and Rushing EJ. WT1 and Bcl2 expression in melanocytic lesions of the conjunctiva. Arch Ophthalmol. 2009;127:964-9.

4. McGill G, Horstmann M, Widlund H. BCL2 regulation by the melanocyte master regulator Mitf modulates lineage survival and melanoma cell viability. Cell. 2002;109:707-18.

\section{Polimorfismo en la secuencia CAG en el exon 1 del gen $I T-15$ asociado a enfermedad de Huntington}

Alexandra Gómez, Antonio Bermúdez

Grupo de Genética, Subdirección Red Nacional de Laboratorios, Instituto Nacional de Salud, Bogotá, D.C., Colombia

ngomez@ins.gov.co

Introducción. La enfermedad de Huntington es una patología que afecta los núcleos basales de ambos hemisferios cerebrales, causando un trastorno motor manifestado principalmente por marcha atáxica y diversas repercusiones en la esfera cognitiva. Su inicio es tardío, a los 30-40 años. Es de origen autosómico dominante por mutación expresada en la amplificación del número de repeticiones de tripletas CAG en el gen IT15 del exón 1 localizado en 4p16.3. El alelo normal contiene hasta 36 repeticiones, por lo general, y la enfermedad se manifiesta si es mayor. Este gen consta de 67 exones y codifica para la proteína huntingtina.

Objetivo. Establecerlametodologíaparadeterminar el tamaño de los alelos con la secuencia repetititva CAG mediante electroforesis capilar y definición de homocigocidad en geles de acrilamida. 
Materiales y métodos. Se tomaron muestras de sangre completa, y se hizo la extracción de ADN con el kit PureLink Genomic DNA ${ }^{\mathrm{TM}}$; el fragmento de CAG se amplificó por PCR; la secuenciación del producto amplificado se efectuó con BigDye Terminator $^{\mathrm{TM}}$, versión 3.1 ; la purificación de la secuencia se obtuvo con el kit BigDye Xterminator Purification $^{\mathrm{TM}}$ y al producto obtenido se le determinó la secuencia CAG por electroforesis capilar en el analizador $A B I$ Prism $310^{\mathrm{TM}}$. La secuencia resultante fue evaluada usando el software Sequencing Analysis' ${ }^{\mathrm{TM}}$, versión 5.4. Los cebadores de amplificación fueron diseñados según los estándares reportados en la literatura.

Resultados. Se estableció la metodología para la secuenciación y definición alélica, para determinar la condición de portadores de la mutación. En las muestras analizadas a la fecha se encontraron entre 17 y 21 repeticiones.

Conclusión. La metodología de electroforesis capilar, complementada con el análisis de geles de poliacrilamida, es una herramienta útil para el diagnostico de la enfermedad de Huntington.

Palabras clave: enfermedad de Huntington, secuenciación, repeticiones CAG, IT-15, electroforesis capilar.

\section{Referencias}

1. A novel gene containing a trinucleotide repeats that is expanded and unstable on Huntington's disease chromosomes. Cell. 1993;72:971-83.

2. Langbhen DR, Brinkman RR, Faulsh D, Paulsen JS, Hayden MR, on behalf of the International Huntington's Disease Collaborative Group. A new model for prediction of the age of onset and penetrante for Huntington's disease based on CAG length. Clin Genet. 2004;65:267-77.

3. Paradisi I, Hernández A, Arias S. Huntington disease mutation in Venezuela: age of onset, haplotype analyses and geographic aggregation. J Hum Genet. 2008;53:127-35.

\section{Análisis cualitativo de los documentos de análisis de las demoras de las muertes maternas en Bogotá, 2009}

\section{Eddier Martínez}

Grupo ASIS, Subdirección de Vigilancia y Control en Salud Pública, Instituto Nacional de Salud, Bogotá, D.C., Colombia emartinez@ins.gov.co

En: Inf Quinc Epidemiol Nac. 2011;16(5): en revisión

Objetivo. A partir del modelo de las cuatro demoras para la atención oportuna de las mujeres gestantes, que consiste en: 1) reconocimiento del problema, 2) oportunidad de la decisión y de la acción, 3) acceso a la atención y logística de referencia, y 4) calidad de la atención, en el presente estudio se analizaron algunos de los materiales producidos durante el año 2009 por el personal encargado de la recolección de información y análisis de las muertes maternas de la Secretaría Distrital de Salud de Bogotá.

Materiales y métodos. El material proporcionado por el Grupo Maternidad Segura del Instituto Nacional de Salud constaba de 36 de los 73 casos de mortalidad materna que se presentaron en la capital durante el 2009, y dos casos provenientes de otros municipios. La documentación analizada incluía: historias clínicas, investigaciones de caso y actas de análisis de cada mortalidad materna. Con un enfoque cualitativo, se revisó, seleccionó y categorizó el material a partir del modelo de las demoras.

Resultados. Se evidencia que en algunas situaciones las demoras fueron determinantes de las muertes maternas, a pesar de la respuesta social e institucional. En $87 \%$ de los casos se identificó falta de cumplimiento de las mujeres gestantes a los programas de prevención y promoción de las instituciones sanitarias, así como desconocimiento de su situación de potencial riesgo al encontrarse en estado de embarazo (demora 1), mientras que $89,5 \%$ de los casos estuvieron asociados con problemas en la calidad en la atención (demora 4).

Conclusión. Los procesos de vigilancia deben tener en cuenta: 1) que la recolección de información debe garantizar la calidad mejorando la exactitud y trazabilidad de los datos; 2) con relación al papel de los expertos que participan del proceso de vigilancia, es necesario cualificar en técnicas de recolección y registro de datos cualitativos al personal encargado de las investigaciones de caso y establecer un formato de acta de comités de análisis más adecuado, y 3) los análisis efectuados en los comités de mortalidad materna deben estar orientados a acciones concretas para detectar e intervenir posibles fallas en el sistema de atención en salud.

Palabras clave: mortalidad materna, Bogotá, demoras, determinantes sociales, salud pública.

\section{Referencias}

1. Berg C, Danel I, Mora G. Guidelines for maternal mortality epidemiological surveillance. Washington, D.C.: Pan American Health Organization; 1996. 
2. Nachbar N, Baume C, Parekh A, Project M. Assessing safe motherhood in the community: a guide to formative research: mother care. New York: John Snow, Inc.; 1998.

3. OPS. La mortalidad materna en las Américas. Boletín Epidemiológico OPS. 1993;14(1).

4. Bureau PR, Ransom El, Yinger NV. Por una maternidad sin riesgos: cómo superar los obstáculos en la atencin a la salud materna. Population Reference Bureau; 2002.

5. Vélez LG, Álvarez GAV, Jaramillo BA. Panorama de la mortalidad materna. En: Gallego L, Gómez J, Escobar A, editores. Modelos para el análisis de la mortalidad materna y perinatal. Medellín: Alcaldía de Medellín, Secretaría de Salud; 2005.

6. Carrillo A. Mortalidad materna en Colombia: reflexiones en torno a la situación y la política pública durante la última década. Rev Cienc Salud. 2007;5(2).

7. Giraldo CV, Ceballos GY. Acostumbrarse a las barreras: estudio cualitativo de las barreras del sistema de salud colombiano para el diagnóstico y tratamiento oportuno de cáncer de mama. Forum: Qualitative Social Research. 2011;12(2).

8. Abadía CE, Oviedo DG. Bureaucratic itineraries in Colombia. A theoretical and methodological tool to assess managedcare health care systems. Social Science \& Medicine. 2009;68:1153-60.

9. Strauss AL, Corbin JM. Bases de la investigación cualitativa. Técnicas y procedimientos para desarrollar la teoría fundamentada. Medellín: Editorial Universidad de Antioquia; 2002.

\section{Factores de riesgo asociados a la hemorragia posparto en la población registrada en el sistema de información perinatal del distrito de Bogotá, 2009}

Iván Pérez, Andrea Rodríguez, Diana Díaz, Luis Gómez, Claudia Huguett, Lorena González, Brian Gómez, Maribel Ramírez, Hernán Quijada

Grupo ASIS, Subdirección de Vigilancia y Control en Salud Pública, Instituto Nacional de Salud, Bogotá, D.C., Colombia.

iperez@ins.gov.co

Publicado en: Inf Quinc Epidemiol Nac. 2011;16(2)

Introducción. En el presente estudio se utilizaron los datos del Sistema Informático Perinatal entre enero y diciembre de 2009, con el fin de identificar los factores de riesgo asociados a la hemorragia posparto en mujeres gestantes del distrito de Bogotá. Algunos de los factores demográficos evaluados fueron la edad y la ocupación de la mujer gestante; de carácter obstétrico, el número de gestaciones; antecedentes familiares, como diabetes e hipertensión, entre otros; factores relacionados con la morbilidad, como la presencia de enfermedades durante el embarazo, cardiopatía, ruptura prematura de membranas, etc., y factores de riesgo asociados con la atención del parto, como la terminación instrumental del parto y la realización del partograma, todas con el fin de poder orientar las acciones para la prevención de este evento como una de las principales causas obstétricas directas de la mortalidad materna.

Materialesymétodos. Sehizoelanálisis descriptivo univariado y bivariado, estudiando la asociación de la variable dependiente (hemorragia posparto) y las variables independientes mediante el cálculo de odds ratios ajustados por Mantel-Haenszel con sus respectivos intervalos de confianza del $90 \%$, para medir la fuerza de asociación. Finalmente, se desarrolló un análisis multivariado de regresión logística, buscando explicar los factores de riesgo asociados a la hemorragia posparto; algunos de los factores estudiados en este análisis surgieron como resultado del análisis bivariado $(p<0,1)$.

Resultados.Sedescribieronalgunascaracterísticas sociodemográficas de riesgo biológico, factores hereditarios y otras relacionadas con la calidad en la atención del parto. En este análisis, la terminación instrumental del parto $(p=0,031)$ y los antecedentes familiares de diabetes $(p=0,001)$ fueron factores de riesgo significativos al $95 \%$ de confianza. El modelo de regresión logística sugiere cinco factores de riesgo que se asocian significativamente al $90 \%$ de confianza; éstos resultaron ser: los antecedentes familiares de diabetes, la edad de la mujer gestante, la aplicación de ocitócicos durante el trabajo de parto, presencia de preeclampsia durante el parto y la terminación instrumental del parto $(p<0,1)$.

Discusión y conclusiones. La anemia se reporta en la literatura como factor de riesgo, sin embargo, en este trabajo no se encontró ninguna asociación. De los casos de mortalidad reportados, ninguno registró hemorragia posparto en la base de datos. Algunos de los factores de riesgo asociados a la hemorragia posparto son potencialmente prevenibles, el riesgo inducido por la edad de la mujer materna se puede minimizar con la introducción de métodos de regulación de la fecundidad y oportunidades de educación, y otros, mejorando los procesos que garanticen la calidad del parto. Se deben estudiar otros factores de riesgo biológico, hereditario y de riesgo en la calidad de la atención del parto que, posiblemente, no se estén contemplando en este instrumento, como son las discrasias sanguíneas, la toma de 
hematocrito para el diagnostico de anemia y los síndromes metabólicos, entre otras.

Palabras clave: mortalidad materna, hemorragia posparto, factores de riesgo.

\section{Referencias}

1. Figueras A, Narváez E, Aguilera C, Laporte JR. Use of erometrine in tropical climates: The complex equilibrium between information, tradition, knowledge and access to drugs. 2003.

2. Quadir G, Is J, Wani S. Controlled cord traction versus minimal intervention technique in delivery of the placenta: A randomized controlled trial. Am J Obstet Gynecol. 1997;177:770-4

3. Ratnam SS, Viegas OAC, Sing K. Magnitude and causes of maternal mortality as a basis for its prevention. Ott Publishers. 1989:80-90.

\section{Factores de riesgo asociados a la mortalidad infantil en Colombia, 2008}

Andrea Yanira Rodríguez, Iván Pérez, Diana Díaz

Grupo ASIS, Subdirección de Vigilancia y Control en Salud Pública, Instituto Nacional de Salud, Bogotá, D.C., Colombia.

arodriguez@ins.gov.co

Introducción. En el presente estudio retrospectivo, analítico, de casos y controles, se utilizaron los datos registrados en la base de certificado de nacido vivo y defunción del DANE en menores de 1 año del 2008,

Objetivo. Identificar los factores de riesgo asociados al bajo peso al nacer en Colombia y poder orientar las acciones para la prevención del mismo mediante el control de los factores asociados identificados.

Materiales y métodos. Se contemplaron como casos 10.517 muertes de menores de un año, y se escogieron cuatro controles por caso. Los criterios de inclusión para los casos fueron: niños nacidos en Colombia que murieron antes de los 11 meses y 29 días, registrados en los certificados de defunción con las variables de departamento de residencia, sexo, peso al nacer, nivel educativo de la madre, estado civil de la madre, raza a la cual se reconoce la madre de su hijo, edad de gestación mayor al $70 \%$. En la primera fase se realizó un análisis univariado de las variables estudiadas por medio de tablas de frecuencias y estadísticas descriptivas, luego, un análisis bivariado en el que se calculó la fuerza de asociación y las razones de disparidad, mediante la prueba de ji al cuadrado y los odds ratios(OR). Se identificó el sexo masculino, el ser soltera, el bajo peso al nacer, pertenecer al régimen subsidiado, los número de partos y la edad de la madre menor de 15 años y mayor de 45 años, como factores de riesgo asociados a la mortalidad infantil.

Resultados. De acuerdo con el área de ocurrencia de las muertes en niños menores de 1 año para Colombia, 95,4 \% se registraron en la cabecera municipal; según el número de casos registrados, se presentó un mayor porcentaje de casos de mortalidad en el periodo neonatal temprano (47 $\%)$, seguido por los casos que se presentaron en el periodo posneonatal (27,7 \%); 53,1\% (5.580) de los casos no consignaron información de raza; $45,6 \%$ pertenecía al régimen subsidiado; según el peso al nacer, 52,6\% de los casos de mortalidad infantil registraron bajo peso al nacer, 89,4\% de los casos tuvo asistencia médica, $45,5 \%$ de los casos registró el nivel educativo de la madre como de escolaridad de secundaria o nivel de estudios superiores. Al clasificar los factores asociados a la mortalidad infantil según su determinación social, se observaron factores biológicos como el sexo masculino, el bajo peso al nacer; factores sociales, como el estado civil de soltera, el que la madre viviera en área rural dispersa, la edad de la madre menor de 15 años y mayor de 45 años, y factores asociados al sistema de salud, como pertenecer al régimen subsidiado del SGSSS y el número de partos como un factor social y de competencia de los servicios de salud.

Conclusiones. El bajo peso al nacer, las edades extremas de la vida de la madre y el ser soltera sugieren condiciones sociales y emocionales difíciles que ponen en riesgo la vida de los menores de 1 año. El que la madre pertenezca al régimen subsidiado del SGSSS, haya tenido varios partos y observe un mayor porcentaje de mortalidad en el periodo neonatal temprana y posneonatal sugieren el desarrollo de procesos que garanticen el desarrollo, seguimiento y control de modelos de atención y de prestación de servicios de salud que incluyan acciones que favorezcan calidad y oportunidad en la atención de la mujer con enfoque diferencial territorial desde su etapa anterior a la concepción, a la gestación y en el momento del parto, así como la comprensión y los patrones de crianza que permitan la identificación temprana de alarmas ante signos de enfermedades transmisibles en los menores de 1 año. 
Palabras clave: mortalidad infantil, bajo peso, régimen subsidiado, estado civil "soltera".

\section{Referencias}

1. Becker G. Desde otra perspectiva...Human capital. New York: Columbia University Press; 1964.

2. Bustello E. Pobreza y desigualdad; 1998. Corredor C, editora, 1999. Schultz T. Human capital; 1968. En:
International Enciclopedia of the Social Sciences, New Cork: McMillan Company. 2. 2. OECD. Starting strong. Early Childhood Education and Care. OECD, 2001.

3. van der Gaag J. From child development to human development. En: Young ME, et al., editors. From early child development to human development - Investing in our children's future. Washington, D.C.: The World Bank; 2002. p. $63-80$. 


\section{RESISTENCIA A ANTIMICROBIANOS}

\section{Mycobacterium kansasii en paciente con síndrome mieloproliferativo, Bogotá, Colombia, 2009}

Yolanda Rocío Burbano', María Consuelo Garzón', Juan Bueno ${ }^{1}$, Karen Cubillos ${ }^{1}$, Lucy Angeline Montaño², Andrés Montilla ${ }^{2}$

${ }^{1}$ Grupo de Micobacterias, Subdirección Red Nacional de Laboratorios, Instituto Nacional de Salud, Bogotá, D.C., Colombia

${ }^{2}$ Grupo de Microbiología, Subdirección Red Nacional de Laboratorios, Instituto Nacional de Salud, Bogotá, D.C., Colombia

yburbano@ins.gov.co

Introducción. Las micobacterias no tuberculosas se encuentran en el ambiente como organismos ubicuos con distribución geográfica y capacidad patógena variada. La ocurrencia de la infección depende del sistema inmune del hospedero. Mycobacterium kansasii es la segunda micobacteria no tuberculosa oportunista después del complejo $M$. avium, asociada con pacientes inmunocomprometidos por $\mathrm{VIH}$, y se ha encontrado en casos con síndromes mieloproliferativos. La presentación más común es la enfermedad pulmonar crónica, además, produce formas diseminadas.

Objetivo. Reportar el caso de una paciente con síndrome mieloproliferativo, con diagnóstico presuntivo de tuberculosos miliar de quien se aisló M. kansasii de una muestra de sangre.

Materiales y métodos. Se realizó la identificación fenotípica y la caracterización genética por secuenciación del gen $16 \operatorname{SrRNA}$, al aislamiento obtenido de una muestra de sangre.

Resultados. El aislamiento se identificó fenotípica y genotípicamente como $M$. kansasii y con homología del $99 \%$, y como M. gastri con homología del 98 $\%$ en NCBI.

Conclusión. Este es el primer caso reportado en Colombia en el que se aisla $M$. kansasii de un paciente con síndrome mieloproliferativo. El caso clínico reportado muestra la importancia de considerar otras condiciones de inmunosupresión diferentes al $\mathrm{VIH}$, como factor de riesgo de las infecciones diseminadas producidas por este microorganismo.

Palabras clave: Mycobacterium kansasii, inmunosupresión.

\section{Referencias}

1. Kim RD, et al. Pulmonary nontuberculous mycobacterial disease: prospective study of a distinct preexisting syndrome. Am J Respir Crit Care Med. 2008;178:1066-74.

2. Griffith DE. Management of disease due to Mycobacterium kansasii. Clin Chest Med. 2002;23:613-21.

3. Hye K, Park HK, et al.. Clinical characteristics and treatment outcomes of Mycobacterium kansasii lung disease in Korea. Yonsei Med J. 2010;51:552-6.

\section{Becegeítis en lactante con inmunosupresión grave, Medellín, Colombia, 2009}

Yolanda Rocío Burbano', María Consuelo Garzón ${ }^{1}$, Juan Bueno', Fabiola Arias $^{2}$, Jorge Fernández ${ }^{3}$

${ }^{1}$ Grupo de Micobacterias, Subdirección Red Nacional de Laboratorios, Instituto Nacional de Salud, Bogotá, D.C., Colombia

${ }^{2}$ Sección de Micobacterias, Instituto de Salud Pública de Chile, Santiago, Chile

${ }^{3}$ Sección de Genética Molecular, Instituto de Salud Pública de Chile, Santiago, Chile

yburbano@ins.gov.co

Introducción. Las deficiencias en la inmunidad celular, de origen primario o adquirido, hacen más susceptible a los pacientes de presentar complicaciones postvacunales como la producidapor la vacunación con BCG (bacilo de Calmette-Guérin), conocida como becegeítis, la cual se desarrolla de manera localizada y, en algunos casos, puede darse el paso de la BCG al torrente sanguíneo resultando en un proceso mucho más grave y con síntomas serios, que se denomina becegeosis.

Objetivo. Reportar el caso de un lactante desnutrido y con inmunodeficiencia grave de quien se aisló Mycobacterium bovis BCG a partir de una muestra de sangre.

Materiales y métodos. De un niño de 6 meses de edad con desnutrición grave, bajo peso al nacer e inmunodeficiencia grave, se aisló de sangre una micobacteria, la cual fue procesada para su identificación fenotípica en el Laboratorio Nacional de Referencia del Instituto Nacional de Salud y enviada para su tipificación por biología molecular en el Instituto de Salud Pública de Chile.

Resultados. Se identificó mediante pruebas bioquímicas, pruebas de sensibilidad y clasificación 
molecular, usando el método GenoType ${ }^{\circledR}$ MTBC Mycobacterium bovis BCG.

Conclusión. Se desconoce la incidencia real de las complicaciones asociadas a la vacuna BCG, sin embargo, es considerada como una vacuna segura; en la literatura se señala una frecuencia mundial estimada de efectos adversos entre 0,1 y $3,5 \%$. Las inmunodeficiencias graves explican la mayoría de los casos, como la enfermedad granulomatosa crónica de la infancia, la enfermedad de DiGeorge completa y el sida.

Palabras clave: Mycobacterium bovis BCG, becegeosis, inmunosupresión.

\section{Referencias}

1. Lichtenauer-Kaligis EG, et al. Severe Mycobacterium bovis BCG infections in a large series of novel IL-12 receptor beta1 deficient patients and evidence for the existence of partial IL-12 receptor beta1 deficiency. Eur J Immunol. 2003;33:59-69.

2. Hatherill M. Prospects for elimination of childhood tuberculosis: The role of new vaccines. Arch Dis Child. 2011.

3. Macías-Parra $\mathrm{M}$, et al. Enfermedad diseminada fatal por vacuna BCG en un paciente con inmunodeficiencia combinada severa. Acta Pediatr Mex. 2006;27:145-5.

\section{Tuberculosis cutánea asociada a desastre natural, Girón, Santander, 2005}

Graciela Mejía1, Dora Leticia Orjuela¹, Yolanda Rocío Burbano1, María Consuelo Garzón', Claudia Marcela Castro², Gloria Mercedes Puerto², Ivonne Agudelo $^{3}$, Juan Bueno ${ }^{1}$

1 Grupo de Micobacterias, Subdirección Red Nacional de Laboratorios, Instituto Nacional de Salud, Bogotá, D.C., Colombia

2 Grupo de Micobacterias, Subdirección Investigación, Instituto Nacional de Salud, Instituto Nacional de Salud, Bogotá, D.C., Colombia

3 Liga Santandereana Contra el Cáncer, Bucaramanga, Colombia

gmejia@ins.gov.co

Introducción. La tuberculosis cutánea por inoculación primaria resulta de la introducción directa de Mycobacterium tuberculosis en la piel de una persona que no posee inmunidad natural ni adquirida frente a este microorganismo. De rara presentación, constituye el $0,1 \%$ de la consulta dermatológica.

Objetivo. Presentar un caso de tuberculosis cutánea posterior a la inoculación de barro contaminado durante la primera ola invernal del 2005 en Girón, Santander.

Materiales y métodos. Se procesó la biopsia de la piel inguinal de una lesión nodular indurada proveniente de un paciente con trauma en piel, provocado durante un desastre natural (desbordamiento del río Oro y varias de sus quebradas afluentes en el área suburbana de Girón) para cultivo, baciloscopia, identificación fenotípica y genotípica, y pruebas de sensibilidad a fármacos.

Resultados. La baciloscopia fue negativa para bacilos acido-alcohol resistentes; a la sexta semana en medio Ogawa, se observó crecimiento lento de colonias no cromógenas. La identificación fenotípica las clasificó como M. tuberculosis, cuyo género se confirmó por PCR mediante la amplificación del gen groEL y hsp 65. Las pruebas de sensibilidad reportaron resistencia a isoniacida y estreptomicina.

Conclusión. La tuberculosis cutánea es una enfermedad inusual; su incidencia es escasa; actualmente, representa menos del $0,5 \%$ de todos los casos vistos de tuberculosis. La relación entre desastres naturales y enfermedades infecciosas es frecuente. Este reporte de caso demuestra la importancia de hacer una historia clínica y un examen físico adecuados, así como de disponer de un diagnóstico oportuno que determine la etiología del agente infeccioso causante de esta patología de rara presentación.

Palabras clave: tuberculosis cutánea, inoculación primaria, desastre natural.

\section{Referencias}

1. Kim JK, et al. Three cases of primary inoculation tuberculosis as a result of illegal acupuncture. Ann Dermatol. 2010;22:341-5.

2. Bravo FG, Gotuzzo E. Cutaneous tuberculosis. Clin Dermatol. 2007;25:173-80.

3. Watson JT, et al. Epidemics after natural disasters. Emerg Infect Dis. 2007;13:1-5. 


\section{TOXICOLOGÍA AMBIENTAL}

\section{Estandarización y validación de una metodología analítica de extracción líquido-líquido y cromatografía de gases acoplada a masas para la determinación de plaguicidas organofosforados y carbamatos en muestras de sangre}

Ronald Gustavo López, Alejandra Fernández, Andrés Antonio Monroy, Marcela Eugenia Varona

Grupo de Salud Ambiental y Laboral, Subdirección de Investigación, Instituto Nacional de Salud, Bogotá, D.C., Colombia

mvarona@ins.gov.co

Introducción. Las crecientes exigencias de calidad y la necesidad de optimizar el proceso de análisis en el laboratorio hacen necesario disponer de metodologías estandarizadas y validadas, que puedan determinar resultados exactos, precisos y confiables en la determinación de plaguicidas.

Objetivo. Realizar la estandarización y validación de una metodología analítica para la determinación de plaguicidas organofosforados y carbamatos en muestras de sangre por extracción líquido-líquido y cromatografía de gases acoplada a espectrometría de masas.

Materiales y métodos. Se cuantificaron seis plaguicidas organofosforados y seis carbamatos en $1,0 \mathrm{ml}$ de sangre de pacientes ocupacionalmente expuestos, mediante extracción líquido-líquido con acetato de etilo y concentración mediante evaporación al vacío, empleando el RapidVap® y posterior análisis cuali-cuantitativo en el cromatógrafo de gases acoplado a un detector selectivo de masas.

Resultados. Se obtuvo un método lineal con coeficientes de correlación entre 0,95 y 0,99 y una precisión expresada como coeficiente de variación menor al $15 \%$ para cada una de las concentraciones evaluadas; la exactitud, expresada como el porcentaje de recuperación, fue en promedio superior al $80 \%$. Los analitos no presentaron degradación alguna en las pruebas de corto y mediano plazo, ni en los ciclos de congelación y descongelación.

Conclusión. El método de análisis de plaguicidas en muestras de sangre empleando la cromatografía de gases acoplada a masas presenta una alta exactitud, precisión y sensibilidad. Su uso aporta una gran especificidad y selectividad al método, lo que reduce nuevos procesos y repeticiones en los análisis y permite dar respuestas confiables y oportunas para el seguimiento de trabajadores expuestos a plaguicidas inhibidores de colinesterasa.

Palabras clave: plaguicidas organofosforados, plaguicidas carbamatos, estandarización, validación, extracción líquido-líquido, cromatografía de gases acoplada a masas.

\section{Referencias}

1. Idrovo A. J. intoxicaciones masivas con plaguicidas en Colombia. Biomédica. 1999;19:67-76.

2. Department of Health and Human Services. Food and Drug Administration. Guidance for industry. Bioanalytical method validation. 2009

3. López F, Beltrán J, Forcada M, Hernández F. Comparison of simplified methods for pesticide residue analysis. Perpectivas en Salud Pública. 1998;18.

\section{Sistema de información de la vigilancia de la calidad del agua potable, SIVICAP}

Gerardo Nava, Ángela Mejía, Jorge Soler, Lady Flórez, Jaime E. Ortiz q.e.p.d.

Grupo de Salud Ambiental, Subdirección Red Nacional de Laboratorios, y Oficina de Sistemas, Instituto Nacional de Salud, Bogotá, D.C., Colombia

gnavat@ins.gov.co

Publicado en: Rev Salud Ambient. 2009;9(1) y Biomédica. 2002;22(Suppl.):53.

Introducción. El Grupo de Salud Ambiental y la Oficina de Sistemas del Instituto Nacional de Salud desarrollaron el aplicativo Sivicap 1.0 en el 2001, para sistematizar la información recolectada por las autoridades sanitarias sobre la vigilancia del agua consumida en el país. Inicialmente, la información fue voluntaria pero dada la utilidad mostrada para el sector de aguas, se reglamentó como sistema de información oficial de la vigilancia en el país en el Decreto 1575/07 del Ministerio de la Protección Social y MAVDT.

Objetivo. Fortalecer el subsistema Sivicap para calcular indicadores y demás requisitos contemplados en el Decreto 1575 de 2007 y resoluciones reglamentarias, que permitan supervisar, prevenir y controlar los riesgos para la salud humana relacionados con el agua. 
Materiales y métodos. El Instituto Nacional de Salud desarrolló la versión Sivicap 1.8 en plataforma Windows XP® en el 2007, sistematizando la información requerida en las Resoluciones 2115/07 y 0811/08, generando reportes técnicos integrados de índices de riesgo por calidad de agua e índices de riesgo por abastecimiento de agua, del agua que consume el país.

Resultados. Actualmente, las 33 secretarías departamentales de salud y la distrital, envían información que es publicada en la página web del Instituto Nacional de Salud, cuyos reportes son consultados para toma de decisiones, por entidades de salud pública, servicios públicos de aguas, entidades de vigilancia y control, gobernaciones, alcaldías, ONG y ciudadanía en general.

Conclusión. El aplicativo permite visibilizar la calidad del agua en el país; actualmente, se está realizando la tercera fase para implementar el nuevo Sivicap en página web para uso en línea en tiempo real y enlaces a otros sistemas de información a partir del 2012.

Palabras clave: sistemas de Información, calidad del agua, vigilancia en salud, salud ambiental.

\section{Referencias}

1. Decreto 1575 de 2007, por el cual se establece el Sistema para la Protección y Control de la Calidad del Agua para Consumo Humano, y sus resoluciones regulatorias.

2. Guzmán B, Bevilacqua D, Bastos KX, Nava I. Análisis comparativo de las estrategias operativas empleadas en los sistemas nacionales de VQACH de Brasil y Colombia. Revista de Salud Ambiental. 2009;9:1-165.

3. Ortiz JE, Bonilla H, Nava G, Arrieta G, Fontal P, Ardila A. Sistema de información para la vigilancia de la calidad del agua potable, Sivicap. Biomédica. 2002;22(Sup.1).:53.

4. Guía para la vigilancia y el control de calidad de agua para consumo humano, OPS/CEPIS/PUB/02.79, 2002.

\section{Efectos en la salud y el medio ambiente por el uso de plaguicidas en el cultivo de tomate en el municipio de La Merced, Caldas, 2011}

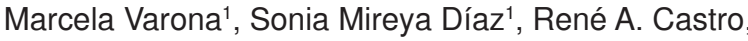
Martha Isabel Páez, Natalia Carvajal, Edwin Barbosa, Lina María León

1 Grupo de Salud Ambiental y Laboral, Subdirección de Investigación, Instituto Nacional de Salud, Bogotá, D.C., Colombia

2 Instituto Colombiano Agropecuario, Bogotá, D.C., Colombia
3 Universidad del Quindío, Armenia, Colombia

4 Universidad del Valle, Cali, Colombia

5 Dirección Territorial de Salud de Caldas, Manizales, Colombia

mvarona@ins.gov.co

Introducción. En Colombia, la agricultura constituye uno de los principales rubros de ingreso, ocupando aproximadamente el $40 \%$ de la fuerza laboral y representando el $50 \%$ de las divisas del país.

Objetivo. Reducir los posibles efectos adversos en la salud y el medio ambiente por el uso de plaguicidas en zonas productoras de Colombia mediante la implementación de las buenas prácticas agrícolas en el cultivo de tomate.

Materiales y métodos. Se realizó un estudio descriptivo en el municipio de La Merced, departamento de Caldas, el cual contempló tres fases: la primera, de diagnóstico, en la que se seleccionaron 132 trabajadores del sector agrícola y se recolectaron muestras biológicas y ambientales; la segunda, de intervención en la cual se incluyeron 5 parcelas en las que se implementaron las buenas prácticas agrícolas, y la última fase, la evaluación de las parcelas demostrativas.

Resultados. El tiempo de exposición a los plaguicidas osciló entre tres meses y 35 años, con un promedio de exposición de nueve años. Se encontraron niveles de plaguicidas organoclorados en el 97,0 \% (128), e inhibición de la enzima acetilcolinesterasa en el 34,1 \% (45) de los participantes. En cuanto a las muestras ambientales se encontraron niveles de plaguicidas organofosforados en el tomate y en el suelo. En el agua y lodo se detectaron niveles de plaguicidas organoclorados.

Conclusión. Se ponen de manifiesto todos los riesgos asociados al uso de plaguicidas y la implementación de las buenas prácticas agrícolas que permiten reducir los potenciales efectos adversos sobre la salud que pueden producir estas sustancias químicas.

Palabras clave: plaguicidas, tomate, exposición ocupacional, exposición ambiental, biomarcadores.

\section{Referencias}

1. Idrovo AJ. intoxicaciones masivas con plaguicidas en Colombia. Biomédica. 1999;19:67-76.

2. Barr D. Biomonitoring of exposure to pesticides. Chem Health Saf. 2008;15:20-9.

3. Chakraborty S, Mukherjee S, Roychoudhury S, Siddique $\mathrm{S}$, Lahiri T, Ray M. Chronic exposures to cholinesterase- 
inhibiting pesticides adversely affect respiratory health of agricultural workers in India. J Occup Health. 2009;51:488-97.

\section{Evaluación de los efectos de los plaguicidas sobre la población habitante de la ribera del río Bogotá en el municipio de Suesca, Cundinamarca, 2010}

Marcela Varona ${ }^{1}$, Sonia Mireya Díaz ${ }^{1}$, Jaime Fernando González, Alejandra Salcedo, Adriana Rodríguez

1 Grupo de Salud Ambiental y Laboral, Subdirección de Investigación, Instituto Nacional de Salud, Bogotá, D.C., Colombia

2 Universidad Nacional de Colombia, Bogotá, D.C., Colombia

3 Universidad del Rosario, Bogotá, D.C., Colombia

4 Fundación al Verde Vivo, Bogotá, D.C., Colombia mvarona@ins.gov.co

Introducción. El río Bogotá presenta una alta carga de contaminación secundaria al vertimiento de residuos de plaguicidas procedentes de los cultivos ubicados en su cuenca alta.

Objetivos. Establecer los niveles de plaguicidas organofosforados, carbamatos, ditiocarbamatos y organoclorados en muestras biológicas de habitantesdelmunicipio deSuesca(Cundinamarca), en muestras de pez Capitán y en agua del río Bogotá.

Materiales y métodos. Se seleccionaron 101 habitantes de la zona ribereña del río a quienes se les realizó una encuesta y se les evaluó la actividad de la enzima acetilcolinesterasa; se midieron los niveles de organoclorados en sangre y del metabolito etilentiourea en orina. Se determinaron los cambios morfológicos e histológicos de 36 peces Capitán y se les evaluó la actividad de la acetilcolinesterasa en cerebro y músculo. Se analizaron los diferentes plaguicidas en muestras de agua del río.

Resultados. El $39 \%$ de los habitantes evaluados se encontraban expuestos ocupacionalmente a plaguicidas. Ninguno de ellos presentó niveles de inhibición de la enzima acetilcolinesterasa, 4 $\%$ presentaba valores positivos para etilentiourea y $88 \%$ un valor positivo para alguno de los 11 organoclorados evaluados. Para el pez Capitán, se detectaron niveles de organofosforados en 14 muestras y niveles de organoclorados en 27 de las 36 muestras evaluadas. En 5 de las 6 muestras de agua se detectaron niveles de organoclorados y organofosforados.

Conclusión. La presencia de plaguicidas organoclorados se comporta como un factor de riesgo para la salud de los habitantes de la ribera del río Bogotá y del pez Capitán en el municipio de Suesca.

Palabras clave: plaguicidas, biomarcadores, peces, agua, río Bogotá.

\section{Referencias}

1. Ecobichon D. Pesticide use in developing countries. Toxicology. 2001;160:27-33.

2. Thundiyil J, Stober J, Besbelli N, Pronczuk J. Acute pesticide poisoning: a proposed classification tool. Bull World Health Org. 2008;86:205-9

3. Tsukinoa $H$, Hanaokaa $T$, Sasakib $H$, Motoyamab $H$, Hiroshimab M, Tanakab T, Kabutoc M, et al. Fish intake and serum levels of organochlorines among Japanese women. Sci Total Environ. 2006;359:90-100.

\section{Estandarización y validación de un método para la determinación de residuos de carbamatos en aguas, usando la técnica de derivación poscolumna y posterior detección por fluorescencia}

Danilo Riaño, Luis Carlos Martínez

Grupo de Salud Ambiental, Subdirección Red Nacional de Laboratorios, y Oficina de Sistemas, Instituto Nacional de Salud, Bogotá, D.C., Colombia driano@ins.gov.co

Introducción. El uso de productos comerciales de carácter fitosanitario se ha visto incrementado en los últimos años debido a la alta competitividad del mercado comercial agrícola ya que se requiere mayor producción y calidad en los diferentes productos. Esto ha generado la aparición y el uso de pesticidas más específicos para el manejo de plagas. A nivel de salud ambiental, tanto en vigilancia como en control, es relevante realizar determinaciones cuantitativas de los residuos de pesticidas sobre matrices ambientales y sobre matrices biológicas, teniendo en cuenta las regiones de fumigación y las poblaciones directamente afectadas en este proceso.

Objetivo. Estandarización y validación de HPLC para la determinación de pesticidas de la familia metilcarbamatos empleando la derivación poscolumna y la detección por fluorescencia. 
Materiales y métodos. Para la determinación se empleó un cromatografo HPLC Agilent $1200 \AA$, columna C18 para elución por gradiente metanol:agua, derivación poscolumna mediante mezcla o-ftalaldehído y tioflúor, y detección por fluorescencia.

Para el estudio de metilcarbamatos se empleó aldicarb, carbofurán, tiodicarb y carbarilo.

Resultados. Se pretendió validar la determinación de aldicarb, carbofurán, tiodicarb y carbarilo sobre la matriz de agua potable, y marcar las condiciones de partida para la detección en aguas superficiales y matrices biológicas. Una vez validado el método, será una herramienta de aplicación fundamental en salud ambiental, ya que se podrán determinar cuantitativamente dichos pesticidas en caso de contaminación ambiental y, por otro lado, se podrán realizar estudios comparativos entre la técnica Limperos y Ranta contra la determinación cuantitativa por HPLC.

Conclusión. Se determinaron los parámetros de desempeño para la metodología de análisis de aldicarb, carbofurán, tiodicarb y carbarilo en agua.

Palabras clave: metilcarbamatos, validación, derivación poscolumna.

\section{Referencias}

1. Method EPA 531.1. Measurement of N-methylcarbamoyloximes and $\mathrm{N}$-methylcarbamates in water by direct aqueous injection HPLC with post-column derivatization.

2. Moye HA, Sherrer SJ, St. John PA. Dynamic labeling of pesticides for high performance liquid chromatography: detection of $\mathrm{N}$-methylcarbamates and o-phthaladehyde. Anal Lett. 1977;10:1049.

3. National Pesticide Survey Method No. 5,. Measurement of $\mathrm{N}$-methylcarbamoyloximesand $\mathrm{N}$-methylcarbamates in groundwater by HPLC with post column derivatization.

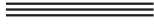

\section{Optimización del sistema de detección para la determinación de aluminio, cobre y hierro en agua para consumo humano, por espectrofotometría molecular utilizando como acomplejante rojo de alizarina $\mathrm{S}$ para el análisis simultáneo por técnicas de calibración multivariante}

\section{Luis Carlos Martínez, Danilo Alfonso Riaño}

Grupo de Salud Ambiental, Subdirección Red Nacional de Laboratorios, Instituto Nacional de Salud, Bogotá, D.C., Colombia

Icmartinez@ins.gov.co
Introducción. La espectrometría molecular se ha convertido en los últimos tiempos en una herramienta de análisis que se ha visto relegada por la aparición de nuevas técnicas de análisis instrumental, más sensibles y precisas. Sin embargo, debido al alto costo de estos equipos y al poco acceso de los mismos en los laboratorios de salud pública de la Red Nacional de Laboratorios, se ha visto la necesidad de desarrollar técnicas de alta sensibilidad y de bajo costo para el análisis de aguas para consumo humano.

En la primera fase del presente estudio se determinaron los parámetros óptimos para la detección de tres metales en agua, hierro, aluminio y cobre. Estos resultados permitirán el desarrollo de una técnica que combina la espectrofotometría molecular UV-vis y poderosas herramientas estadísticas, en la detección simultánea de dichos metales en aguas para consumo humano.

Objetivo. Desarrollar una técnica de análisis de bajo costo que permita la detección simultánea de tres metales (hierro, cobre y aluminio) en aguas para consumo humano.

Materiales y métodos. Para llevar a cabo el objetivo se utilizará un espectrofotómetro UV/vis de canal sencillo y soluciones estándar de aluminio, hierro y cobre.

Resultados. La estandarización preliminar mostró que para el sistema Fe-ARS se obtuvo una linealidad entre 1 y 3 ppm; para el sistema CuARS, entre 1 y 4 ppm, y para el sistema Al-ARS entre 0,5 y $1 \mathrm{ppm}$, todas con una concentración de $4,59 \times 10^{-4} \mathrm{M}$ de acomplejante y con solución reguladora de $\mathrm{pH} 0,08 \mathrm{M}$ y $\mathrm{pH} 5$

Conclusión. Estos resultados parciales demuestran la viabilidad de la implementación de la metodología planteada de análisis simultáneo.

Palabras clave: espectrofotometría molecular, contaminantes en agua, aluminio, hierro, cobre, rojo de alizarina $\mathrm{S}$, calibración multivariante.

\section{Referencias}

1. Gargallo R, Tauler R. Aplicaciones de la quimiometría en el ambito de la industria química. Disponible en: http://www. ub.es/gesq/eq1_cat.htm.

2. Safavi A, Abdollahi $H$, Mirzajani R. Simultaneous spectrophotometric determination of $\mathrm{Fe}$ (III), $\mathrm{Al}$ (III) and $\mathrm{Cu}$ (II) by partial least-squares calibration method. Spectrochim Acta. 2006;63:196-9.

3. Nejati-Yaznidejad M. Spectrophotometric determination of trace amount of copper (II) ion based on complexation with an anthraquinone derivative. Anal Sci. 2006;22:617-9. 


\section{Determinación de cianuro y mercurio en agua}

\section{Carmenza Murillo, Gerardo Nava}

Grupo de Salud Ambiental, Subdirección Red Nacional de Laboratorios, Instituto Nacional de Salud, Bogotá, D.C., Colombia.

cmurillo@ins.gov.co

Introducción. En las zonas auríferas de Colombia, tanto la minería artesanal como la pequeña minería se han caracterizado por la ausencia de organización y por el desconocimiento de los procesos adecuados para la obtención de metales, lo que ha originado problemas ambientales graves que, generalmente, producen contaminación del aire, del suelo y de las fuentes de agua y, frecuentemente, derrames accidentales de cianuro - mercurio en las quebradas y ríos cercanos, empleados por las comunidades para la preparación de sus alimentos.

Objetivo. Desarrollar metodologías analíticas de tipo cualitativo altamente específicas, para el análisis in situ del ión cianuro y del mercurio en agua.

Materiales y métodos. Para el análisis del ión cianuro en agua se seleccionó una metodología basada en su interacción con la vitamina $\mathrm{B}_{12}$. Para la determinación del mercurio en agua se escogió el análisis de espectrofotometría visible y el ensayo cualitativo.

Resultados. Con el método cualitativo para el análisis del ión cianuro, se observó que este es muy específico y que tenía un límite de detección cercano a 3,2 ppm, para la región de fiabilidad, lo que lo hace adecuado para su empleo en situaciones de emergencia en las que este ión puede encontrarse en concentraciones iguales a 400 ppm o mayores. Para la determinación del mercurio, al emplear el método basado en el uso de surfactantes - sustancias que por sus propiedades permiten lograr sistemas de preconcentración simples y eficientes- y ligandos específicos para metales y condiciones óptimas para la separación de fases, se lograron factores de concentración altos: 100X y límites de detección del orden de ppb.

Conclusión. En las zonas auríferas y en las zonas rurales la implementación de estas metodologías analíticas permitirá el análisis del ión cianuro y del mercurio en agua de manera específica.

Palabras clave: cianuro, mercurio, agua, análisis cualitativo

\section{Referencias}

1. Minería de oro artesanal y de pequeña escala. Fecha de consulta: 3 de enero de 2011. Disponible en: www.unido. org.

2. Producción más limpia en la minería del oro en Colombia. Mercurio, cianuro y otras sustancias. Fecha de consulta: 15 de mayo de 2010. Disponible en: www.upme.gov.co.

3. Zelder FH. Specific colorimetric detection of cyanide triggered by a conformational switch in vitamin $\mathrm{B}_{12}$. Inorg Chem. 2008;47:1264-7.

4. Pramauro E, Bianco A. Solubilization in micellar systems: Analytical and environmental applications. Pure Appl Chem. 1995;67:551-9. 


\section{ENFERMEDADES TRANSMITIDAS POR VECTORES Y POR ALIMENTOS}

\section{Ciguatera, revisión de literatura}

Milena Edith Borbón, Jaime Alberto Guerrero

Subdirección de Vigilancia y Control en Salud Pública, Instituto Nacional de Salud, Bogotá, D.C., Colombia jguerrero@ins.gov.co

Introducción. La ciguatera es una enfermedad transmitida por alimentos que ocurre por el consumo de ciertos peces que viven en regiones tropicales y subtropicales que contienen toxinas producidas por un dinoflagelado de la especie Gambierdiscus toxicus.

Objetivo. Realizar una revisión documental de carácter descriptivo del tema a nivel nacional e internacional.

Materiales y métodos. Se realizó una búsqueda en fuentes primarias, secundarias y terciarias de 2000 a 2010, utilizando los términos de referencia: ciguatera, ciguatoxina, dinoflagelados, métodos determinación.

Resultados. Se revisaron 50 documentos entre artículos, guías, folletos y bases de datos; se encontró que las manifestaciones clínicas son variadas y dependen del tipo, cantidad de toxina y susceptibilidad individual; está caracterizada por trastornos gastrointestinales, cardiovasculares y neurológicos, pudiendo ocasionar coma y muerte; su manejo consiste tradicionalmente en el tratamiento de síntomas, soporte y complicaciones.

Aunque la incidencia de intoxicación es baja, se ha estimado que la incidencia mundial puede ser del orden de los 50.000 casos anuales. Esta enfermedad constituye un problema de salud pública, sobre todo en la población residente en las zonas costeras e insulares del país; en Colombia, durante los años 2007-2010, se notificaron al Sivigila 8 brotes que involucraron 62 casos, de los cuales, algunos presentaron secuelas temporales como cefaleas y parestesias.

Conclusiones. Aunque en el país se han reportado casos de ciguatera, no se le ha dado la importancia que merece como problema de salud pública y de impacto económico grave, razón por las cual se deben determinar estrategias interinstitucionales y fijar métodos de diagnóstico, medidas para el manejo y mecanismos de vigilancia y control de esta enfermedad.
Palabras clave: ciguatera, toxinas marinas, ciguatoxina, dinoflagelados, vigilancia en salud pública.

\section{Referencias}

1. Arencibia G, Mancera JE, Delgado G. La ciguatera un riesgo potencial para la salud humana: preguntas frecuentes. Colombia. Universidad Nacional de Colombia, Sede Caribe; 2009.

2. Stewart I, Eaglesham GK, Poole S, Graham G, Paulo C, Wickramasinghe W, Sadler R, Shaw GR. Establishing a public health analytical service based on chemical methods for detecting and quantifying Pacific ciguatoxin in fish samples. Queensland, Australia; 2009.

3. Laurent D, Yeeting B, Labrosse P, Gaudechoux JP. Ciguatera: a field reference guide. Secretariat of the Pacific Community; 2005.

4. Carreño LA, Mera E. Intoxicación alimentaria. En: Taller regional científico de la $\mathrm{COI}$ sobre floraciones de algas nocivas en IOCARIBE-ANCA-IV. San Andrés Islas, 22 a 27 de mayo de 2007. San Andrés Islas: Universidad Nacional de Colombia - Sede Caribe; 2007. p. 31-2.

\section{Biodiversidad de la subfamilia} Phlebotominae (Diptera: Psychodidae) en la Amazonía y Orinoquía colombiana

\section{Cristina Ferro}

Grupo de Entomología, Instituto Nacional de Salud, Bogotá, D.C., Colombia

crisferro@yahoo.com

Presentado en: III Congreso Colombiano de Zoología, Medellín, noviembre de 2010.

Introducción. La subfamilia Phlebotominae cuenta con una amplia diversidad y es reconocida particularmente por el papel que desempeñan algunas de sus especies como vectores de los patógenos causantes de leishmaniasis, bartonelosis y algunas arbovirosis. En el Nuevo Mundo, el número de especies descritas llega a 500. Los países ubicados en el Neotrópico, registran una mayor riqueza de especies y, entre éstos, Colombia ocupa el segundo lugar con 159 especies después de Brasil que registra 242.

Objetivo. Presentar la distribución de las especies de Phlebotominae en la Amazonía y la Orinoquía colombiana.

Materiales y métodos. Los datos de las localidades se obtuvieron a partir de recolecciones de flebótomos realizadas desde la década de los 
sesenta. Las especies se distribuyeron por género siguiendo la clasificación de Galati 2003.

Resultados.Seobtuvierondatosde 100 localidades, aproximadamente, con un total de 96 especies. De éstas, 59 corresponden a registros exclusivos de la Amazonía y Orinoquía mientras que las 37 restantes se comparten con otros departamentos. Las 96 especies obtenidas se distribuyeron en los géneros: Bichromomyia, Brumptomyia, Evandromyia, Lutzomyia, Micropygomyia, Migonemyia, Nyssomyia, Pintomyia, Pressatia, Psathyromyia, Psychodopygus, Sciopemyia, Trichophoromyia, Trichophygomyia, Viannamyia. Los géneros que registraron mayor diversidad fueron Psathyromyia y Psychodopygus con 15 especies cada uno. Desde la perspectiva de la salud pública, son importantes los géneros Psychodopygus. Nyssomyia, Pintomya, Bichromomyia y Lutzomyia por su relevancia epidemiológica como insectos vectores

Conclusión. La gran variedad de especies de Phlebotominae y su amplia distribución confirman la importancia que desde el punto de vista de biodiversidad y salud pública tiene la Amazonía y Orinoquía en Colombia.

Palabras clave: Phlebotominae, mapa, distribución, Amazonía, Orinoquía

\section{Referencias}

1. Cabrera OL, Mosquera L, Santamaría E, Ferro C Flebótomos (Díptera Psychodidae) del departamento de Guaviare, Colombia con nuevos registros para el país. Biomédica. 2009;29:73-86.

2. Galati EAB. Classificação de Phlebotominae. En: Rangel EF, Lainson R, eds. Flebotomineos do Brasil. Rio do Janeiro: Fiocruz,; 2003. p. 23-51.

3. Vivero RJ, Bejarano EE, Castro M, Pérez J, Pérez Doria A Vélez ID, Carrillo LM. Trece registros nuevos de Lutzomyia (Díptera: Psychodidae) para el departamento del Vichada, Orinoquía Colombiana. Biota Neotrop. 2010;2:401-10.

4. Young DG, Duncan M. Guide to the identification and geographic distribution of Lutzomyia and sand flies in Mexico, West Indies, Central and South America (Diptera: Psychodidae). Mem Amer Entomol Inst. 1994;54:1-881.

\section{Identificación de virus de influenza tipo A asociado a casos de mortalidad en Colombia, abril de 2009-abril de 2011}

Juliana Barbosa, Gloria Rey

Laboratorio de Virología, Subdirección Red Nacional de Laboratorios, Instituto Nacional de Salud, Bogotá, D.C., Colombia.

jbarbosa@ins.gov.co
Introducción. Los virus de influenza de tipo A pueden infectar humanos y una variedad de especies animales; estos virus ARN son responsables de epidemias y pandemias. En Colombia se realiza la vigilancia de influenza desde 1997; en el 2009, con la aparición del virus AH1N1 v/09, se intensificó el diagnóstico por laboratorio especialmente en los casos fatales.

Objetivo. Determinar la proporción de identificación de virus de influenza de tipo $\mathrm{A}$ asociado a casos de mortalidad en Colombia, abril de 2009-abril de 2011.

Materiales y métodos. Se procesaron muestras respiratorias de casos con infección respiratoria aguda procedente de diferentes departamentos del país y remitidas al Laboratorio de Virología del Instituto Nacional de Salud para diagnóstico de infección por H1N1 v/09. El ARN viral se obtuvo utilizando QIAamp Viral RNA Mini Kitß (Qiagen); posteriormente, se utilizó el protocolo de RT-PCR en tiempo real de los CDC para la detección y caracterización de los virus influenza de tipo $\mathrm{A}(\mathrm{H} 1$, H3 y H1N1 v/09).

Resultados. Durante el período de estudio se identificaron 3.429 casos de infección por los virus de influenza A, de ellos, 171 (4,98\%) casos fatales. La proporción general de resultados positivos fue mayor para el subtipo A/H1N1 v/09 durante los años 2009 y 2010 (78,8 y 78,2, respectivamente), mientras que para el 2011 correspondió al subtipo A/H3/estacional; en los casos fatales, la proporción de resultados positivos para $\mathrm{A} / \mathrm{H} 1 \mathrm{~N} 1 \mathrm{v} / 09$ ha aumentado anualmente desde su introducción en 2009 (5,1, 6,5 y 11,8, respectivamente)

Conclusión. En el 2011 se presentaron menos casos confirmados y hubo un incremento en la proporción de muertes asociadas a los subtipos $\mathrm{A} /$ H3/estacional y A/H1N1v/09.

Palabras clave: influenza A, Colombia, mortalidad, subtipos.

\section{Referencias}

1. Castro-Jiménez MA, Castillo-Pabón JO, Rey-Benito GJ, Pulido-Domínguez PA, Barbosa-Ramírez J, VelandiaRodríguez DA. Epidemiologic analysis of the laboratoryconfirmed cases of influenza $\mathrm{A}(\mathrm{H} 1 \mathrm{~N} 1) \mathrm{v}$ in Colombia. Eurosurveillance.

2. Yang Y, Sugimoto JD, Halloran ME, Basta NE, Chao DL, Matrajt L, et al. The transmissibility and control of pandemic influenza A (H1N1) virus. Science. 2009;326:729-33.

3. Murphy WB. Orthomyxoviruses. En: Fields BN, Knipe DM, Howlet PM, editors. Field's Virology. Third edition. Philadelphia: Lippincott-Raven Publishers; 1996. p. 1397-445. 


\section{Cambios en genotipos de rotavirus circulantes detectados durante la vigilancia centinela y sus implicaciones para la vacunación en Colombia, 2010}

Claudia Ramírez ${ }^{1,}$ Dioselina Peláez ${ }^{2}$ Johanna

Rodríguez ${ }^{2}$, Mario Ardila²

1 Subdirección de Vigilancia y Control de Enfermedad Diarreica Aguda, Instituto Nacional de Salud, Bogotá, D.C., Colombia

2 Grupo de Virología, Subdirección Red Nacional de Laboratorios, Instituto Nacional de Salud, Bogotá, D.C., Colombia

cramirez@ins.gov.co

Introducción. El rotavirus es la principal causa de diarrea en niños menores de 5 años en todo el mundo. En Colombia se estiman cerca de 246.401 infecciones, 108.417 consultas médicas, 37.258 hospitalizaciones y $\sim 560$ muertes por año en niños menores de 5 años, causados por diferentes genotipos G y P (VP7 describe genotipos G y VP4 describe genotipos $P$ ) de rotavirus. La vacuna monovalente antirotavirus fue introducida para todo el país a partir de 2009.

Objetivo. Identificar cambios en la distribución de genotipos de rotavirus así como nuevas cepas no halladas en etapas previas a la introducción de la vacuna monovalente en el programa regular de vacunación en el país.

Materiales y métodos. Se genotipificaron 70 muestras positivas para rotavirus mediante RTPCR semianidada, previamente estandandarizada en el laboratorio de virología siguiendo el protocolo descrito por los CDC de Atlanta. Las muestras se recolectaron de las regiones central, norte y occidente del país dentro del programa nacional de vigilancia de rotavirus durante 2009 y 2010.

Resultados. El análisis mostró alta frecuencia del genotipo G1P[6], así como del genotipo mixto G1G2P[4]P[6] y una variedad de combinaciones genotípicas con altas frecuencias de G9; este genotipo fue hallado previamente en el país en muy baja frecuencia. De la misma manera, se encontró alta frecuencia del genotipo P6 con gran variedad de genotipos mixtos que contienen G9 y P6.

Conclusión. Estos hallazgos sugieren que la vacuna monovalente que tiene inmunidad cruzada contra cepas pertenecientes al genogrupo [Wa], será retada por los genotipos no [Wa], P[6] G9 identificados en alta frecuencia en nuestro país.
Palabras clave: rotavirus, genotipos, vacuna, Colombia.

\section{Referencias}

1. Clark HF, Lawley DA, Schaffer A, Patacsil JM, Marcello $A E$, Glass RI, et al. Assessment of the epidemic potential of a new strain of rotavirus associated with the novel G9 serotype which caused an outbreak in the United States for the first time in the 1995-1996 season. J Clin Microbiol. 2004;42:1434-8.

2. Sherchand JB, Nakagomi O, Dove W, Nakagomi T, Yokoo M, Pandey BD, et al. Molecular epidemiology of rotavirus diarrhea among children aged $<5$ years in Nepal: predominance of emergent G12 strains during 2 years. J Infect Dis. 2009;200(Suppl.1):S182-7.

3. Ramachandran M, Kirkwood CD, Unicomb L, Cunliffe NA, Ward RL, Bhan MK, et al. Molecular characterization of serotype G9 rotavirus strains from a global collection. Virology. 2000;278:436-44.

\section{Infección simultánea por diferentes serotipos del virus del dengue en dos casos mortales durante un brote en Colombia, 2010}

Jairo A. Méndez, Lissethe C. Pardo, Martha Gracia, Gloria J. Rey

Grupo de Virología, Subdirección Red Nacional de Laboratorios, Instituto Nacional de Salud, Bogotá, D.C., Colombia

jmendez@ins.gov.co

Introducción. El virus del dengue (DENV) es responsable de una importante enfermedad viral reemergente en los países tropicales y subtropicales, que afecta 50 millones de personas al año en todo el mundo. Los brotes en Colombia se producen cada cinco o seis años, aunque la infección es endémica en la mayor parte del país. Durante el último año, Colombia presentó la mayor epidemia de dengue ocurrida en las últimas décadas, con 157.152 casos notificados, 217 muertes confirmadas y los cuatro serotipos virales circulando al mismo tiempo.

Objetivo. Determinar la infección simultánea por serotipos del virus del dengue en pacientes fallecidos durante la epidemia que se presentó en Colombia en el 2010.

Materiales y métodos. Las muestras de dos casos fatales obtenidas de suero y tejidos de los pacientes, se procesaron por RT-PCR utilizando iniciadores específicos de serotipo. La electroforesis en gel demostró amplificación con dos serotipos diferentes (DENV2/DENV3 y DENV2/DENV4, 
respectivamente). Los resultados se confirmaron por secuenciación de los fragmentos amplificados y su posterior análisis por BLAST.

Resultados. En los casos fatales analizados se evidencio infección simultánea por serotipos del virus del dengue; en el paciente con muestra de suero se encontró DENV2/DENV3 y en el paciente con muestra de tejido DENV2/DENV4.

Conclusión. Aunque la circulación de los cuatro serotipos de dengue es común en zonas muy endémicas, la infección simultánea con dos serotipos diferentes sigue siendo un evento muy inusual. Este es el primer reporte de infección simultánea por serotipos del virus del dengue en casos fatales en Colombia. Sin embargo, el papel de la infección simultánea en la seriedad de la enfermedad debe ser más estudiado.

Palabras clave: dengue, dengue grave, infección simultánea, serotipos.

\section{Referencias}

1. Montenegro de Carvalho Araújo F, Ribeiro Nogueira RM, Galvão de Araújo JM, Cavalcante Ramalho IL, Feitosa de Sá Roriz ML, et al. Concurrent infection with dengue virus type-2 and DENV-3 in a patient from Ceará, Brazil. Mem Inst Oswaldo Cruz. 2006;101:925-8.

2. Mamani E, Figueroa D, García MP, Garaycochea MC, Pozo EJ. Infecciones concurrentes por dos serotipos del virus dengue durante un brote en el noroeste de Perú, 2008. Rev Peru Med Exp Salud Pública. 2010;27:16-21.

3. Bharaj P, Chahar HS, Pandey A, Diddi K, Dar L, Guleria R, et al. Concurrent infections by all four dengue virus serotypes during an outbreak of dengue in 2006 in Delhi, India. Virol J. 2008;5:1.

\section{Vigilancia virológica del dengue por el laboratorio, Colombia, enero de 2010- mayo de 2011}

Martha Gracia, Lissethe C. Pardo, Jairo A. Méndez

Laboratorio de Virología, Subdirección Red Nacional de Laboratorios, Instituto Nacional de Salud, Bogotá, D.C., Colombia

mgracia@ins.gov.co

Introducción. En Colombia, se notificaron al Sivigila 157.152 casos de dengue durante el 2010, de los cuales, $94 \%$ correspondieron a dengue (147.670 casos) y el $6 \%$ restante, a dengue grave (9.482 casos).

Objetivo. Determinar los serotipos de dengue circulantes en Colombia, según las muestras recibidas en el Grupo de Virología del 2010 hasta mayo de 2011 dentro de los programas de vigilancia del evento.

Materiales y métodos. Se procesaron 5.154 muestras remitidas por los laboratorios de salud pública del país, las cuales fueron procesadas por técnicas de aislamiento viral en cultivo celular, tipificación por IFI y RT-PCR, y secuenciación.

Resultados. De las 5.154 muestras procesadas durante este periodo, 1.155 resultaron positivas -771 por aislamiento viral-, procedentes principalmente del departamento de Huila, seguido de Boyacá y Putumayo, y 384 por RT-PCR. Mediante estas técnicas virológicas fue posible tipificar los virus circulantes en los diferentes departamentos y se pudo determinar la circulación de los cuatro serotipos virales, con predominio del dengue de tipo 1 (44\%), seguido del dengue 2 (40 $\%)$, dengue $3(13 \%)$ y dengue $4(3 \%)$.

Conclusión. La vigilancia virológica del evento demostró un porcentaje de resultados positivos de $22,4 \%$, superior a los promedios registrados por el grupo en años interepidémicos que no superaba el $10 \%$, lo cual refleja la situación epidémica del país.

Palabras clave: dengue, serotipos, vigilancia virológica, aislamiento viral, RT-PCR

\section{Referencias}

1. Instituto Nacional de Salud. Boletín de vigilancia de dengue en Colombia, № 01 de 2011.

2. Domingo C, Palacios G, Niedrig M, Cabrerizo M, Jabado O, Reyes N, Lipkin WI, Tenorio A. A new tool for the diagnosis and molecular surveillance of dengue infections in clinical samples. Dengue Bulletin. 2004;28:87-95.

3. Méndez JA, Usme-Ciro JA, Domingo C, Rey GJ, Sánchez JA, Tenorio A, Gallego-Gómez JC. Phylogenetic history demonstrates two different lineages of dengue type 1 virus in Colombia. Virol J. 2010;7:226.

\section{Características clínicas y} supervivencia de pacientes con criptococosis meníngea: una comparación entre pacientes positivos y negativos para VIH atendidos en un hospital de tercer nivel en Cúcuta, Norte de Santander, 1995-2010

Jairo Lizarazo², Óscar Chávez², Yeni Peña², Iván Velandia², Patricia Escandón', Clara Inés Agudelo', Elizabeth Castañeda ${ }^{1}$

${ }^{1}$ Grupo de Microbiología, Subdirección de Investigación, Instituto Nacional de Salud, Bogotá, D.C., Colombia 
2 Hospital Universitario Erasmo Meoz, Cúcuta, Colombia.

pescandon@ins.gov.co

Publicado en: Memorias, $8^{\text {th }}$ International Conference on Cryptococcus and Cryptococcosis, 1-5 de mayo de 2011, Charleston, SC, USA

Introducción. La incidencia de la criptococosis en Colombia se ha documentado a través del Programa Nacional de Vigilancia, así como la alta prevalencia de criptococosis por C. gattii en Cúcuta.

Objetivo. Analizar los datos de 1995 a 2010 de los pacientes con criptococosis meníngea atendidos en un hospital de tercer nivel, según el estado de infección por VIH.

Materiales y métodos. Análisis retrospectivo de las historias clínicas de pacientes con criptococosis meníngea que consultaron al hospital durante el período establecido. Se aplicó la prueba de Fisher para determinar las diferencias entre pacientes positivos y negativos para $\mathrm{VIH}$.

Resultados. Se estudiaron 90 casos, 70\% positivos para $\mathrm{VIH}$ y $30 \%$ negativos para $\mathrm{VIH}$. Hubo diferencias estadísticamente significativas $(p \leq 0,05)$ entre los dos grupos en edad y sexo: adultos jóvenes (81 Vs. 28\%), niños (0 Vs. 29.6\%) y proporción hombre:mujer $(3,8$ Vs. 2,4). El curso de los síntomas varió entre 19,3 $\pm 26,9$ días (rango, 1 a 120; media, 10 días) en positivos para VIH a 44,1 \pm 47,7 días (rango, 9 a 240; media, 30 días) en negativos para $\mathrm{VIH}$. No se identificó factor de riesgo en $89 \%$ pacientes negativos para $\mathrm{VIH} ; 70 \%$ de los pacientes positivos para VIH no estaban recibiendo HAART. Cryptococcus neoformans var. grubii se recuperó de todos los pacientes positivos para $\mathrm{VIH}$, mientras que $C$. gattii se identificó en $60 \%$ de los negativos para VIH. La mortalidad hospitalaria fue mayor en positivos para VIH $(49,2$ Vs. $16,0 \%, p<0,001)$

Conclusión. Al comparar estos datos con los de la encuesta, en Cúcuta la criptococosis clínica difiere ampliamente. La prevalencia en niños es mayor y la criptococosis por $C$. gattii predomina en pacientes inmunocompetentes. Por otro lado, la criptococosis en pacientes positivos para VIH tiene un curso crónico.

Palabras clave: criptococosis, meningitis, $\mathrm{VIH}$, Colombia.

\section{Referencias}

1. Lizarazo J, Linares M, De Bedout C, Restrepo A, Agudelo Cl, Castañeda E, Grupo Colombiano para el Estudio de la Criptococosis. Estudio clínico y epidemiológico de la criptococosis en Colombia: resultados de nueve años de la encuesta nacional, 1997-2005. Biomédica. 2007;27:54-64.

2. Lizarazo J, Rodríguez MC, Ordóñez N, Vargas JJ, Castañeda N. Meningitis por Cryptococcus en el Hospital Erasmo Meoz de Cúcuta. Acta Neurol Colomb. 1995;11:259-67.

3. Ordóñez N, Torrado E, Castañeda E. Criptococosis meníngea de 1990 a 1995. Hallazgos del laboratorio. Biomédica. 1996;16:93-7.

\section{Criptococosis por Cryptococcus gattii en Colombia, 1997-2010}

Jairo Lizarazo², Patricia Escandón', Clara Inés

Agudelo ${ }^{1}$, Elizabeth Castañeda ${ }^{1}$

${ }^{1}$ Grupo de Microbiología, Subdirección de Investigación, Instituto Nacional de Salud, Bogotá, D.C., Colombia

2 Hospital Universitario Erasmo Meoz, Cúcuta, Colombia

pescandon@ins.gov.co

Publicado en: Memorias, $8^{\text {th }}$ International Conference on Cryptococcus and Cryptococcosis, 1-5 de mayo de 2011, Charleston, SC, USA

Introducción. Cryptococcus gattii, endémico en varias partes del mundo, afecta principalmente a pacientes inmunocompetentes. Desde 1997 se está realizando en Colombia la vigilancia nacional de criptococosis con el objeto de proveer un estimado de esta micosis en el país.

Objetivo. Analizar los datos de criptococosis por C. gattii recibidos de la Encuesta Nacional durante 1997-2010.

Materiales y métodos. Análisis retrospectivo de las encuestas con dato de cultivo durante el período establecido.

Resultados. De 1.207 encuestas analizadas, se encontraron 41 casos positivos de criptococosis por C. gattii, para una prevalencia del 3,4\%. El 78 $\%$ de los pacientes correspondió a hombres y la edad promedio al diagnóstico fue 40,9 \pm 15,7 años. En $85,4 \%$ de los casos no se identificó el factor de riesgo, mientras que en el $14,6 \%$ restante, el VIH se reportó en 9,8\%.

Las manifestaciones clínicas más frecuentes fueron: dolor de cabeza ( $82,5 \%$ ), náusea y vómito $(57,5 \%)$, alteraciones mentales (50\%), alteraciones visuales (42,5\%), fiebre (40\%), signos meníngeos $(32,5 \%)$ y tos (10\%).

El examen directo fue positivo en $97,4 \%$ de los casos. Cryptococcus gattii se recuperó de 90,2 $\%$ y $9,8 \%$ muestras de líquido cefalorraquídeo y muestras respiratorias, respectivamente. En 38 
casos se determinó el serotipo, y el más prevalente fue el B (89,5\%). En 20 (48,8\%) aislamientos el patrón fue VGII: VGIII en 14 (34,2\%); VGI en 6 (14,6\%) y VGIV en 1 (2,4\%).

Conclusión. La vigilancia pasiva hecha a través de esta encuesta permite estimar que la criptococosis por C. gattiitiene una baja prevalencia en Colombia. Sin embargo, la prevalencia del patrón molecular VGII llama la atención teniendo en cuenta su alta virulencia y potencial para producir brotes.

Palabras clave: criptococosis, Cryptococcus gattii, Colombia.

\section{Referencias}

1. Lizarazo J, Linares M, De Bedout C, Restrepo A, Agudelo Cl, Castañeda E, Grupo Colombiano para el Estudio de la Criptococosis. Estudio clínico y epidemiológico de la criptococosis en Colombia: resultados de nueve años de la encuesta nacional, 1997-2005. Biomédica. 2007;27:54-64.

2. Lizarazo J, Mendoza M, Palacios D, Vallejo A, Bustamante A, Ojeda E, et al. Criptococosis ocasionada por Cryptococcus neoformans variedad gattii. Acta Med.

3. Kidd SE, Hagen F, Tscharke RL, Huynh M, Bartlett KH, Fyfe M, et al. A rare genotype of Cryptococcus gattii caused the cryptococcosis outbreak on Vancouver Island (British Columbia, Canada). PNAS. 2004;101:17258-63.

\section{Caracterización genotípica del patógeno emergente Cryptococcus gattii patrón molecular VGIII}

Carolina Firacative1, Patricia Escandón¹, Jane Sykes, Joao Frade, Shawn Lockhart, Laura Rocío Castañón, Cudberto Contreras, Rubén López, Richard Malik,

Elizabeth Castañeda ${ }^{1}$, Wieland Meyer

1 Grupo de Microbiología, Subdirección de Investigación, Instituto Nacional de Salud, Bogotá, D.C., Colombia

2 Molecular Mycology Research Laboratory, Centre for Infectious Diseases and Microbiology, Sydney Medical School-Westmead, The University of Sydney, Westmead Hospital, Westmead, NSW, Australia.

3 Department of Medicine and Epidemiology University of California, Davis; Centre for Disease Control, Atlanta, GA.

4 Departamento de Microbiología y Parasitología, Facultad de Medicina, Universidad Autónoma de Méjico, Instituto Nacional de Diagnóstico y Referencia Epidemiológicos, Ciudad de México, México.

5 Centre for Veterinary Education, The University of Sydney, Sydney, Australia. pescandon@ins.gov.co

Publicado en: Memorias, $8^{\text {th }}$ International Conference on Cryptococcus and Cryptococcosis, 1-5 de mayo de 2011, Charleston, SC, USA

Introducción. Cryptococcus gattii causa enfermedad grave en pacientes inmunocompetentes. Por estudios moleculares se han identificado cuatro patrones principales (VGI-VGIV); se ha encontrado que el VGII está asociado a brotes en el nordste de los Estados Unidos. Recientemente, el VGIII ha emergido en diferentes partes del mundo.

Objetivo. Establecer la estructura genética de poblaciones del patógeno emergente $C$. gattii con patrón molecular VGIII.

Materiales y métodos. Se recuperaron 67 aislamientos clínicos, ambientales y veterinarios de ocho países: Colombia (17), Guatemala (1), México (13), Nueva Zelanda (1), Paraguay (1), Tailandia (1), Estados Unidos (32) y Venezuela (1). Se analizaron mediante MLST de 7 genes consenso.

Resultados. Se encontraron 42 secuencias tipo, y la ST79 fue la más común (8 aislamientos). La mayoría de los aislamientos se agruparon en tres clados principales, dos de ellos agruparon aislamientos clínicos, ambientales y veterinarios. La población global de $C$. gattii VGIII fue genéticamente muy diversa, con la mayor diversidad encontrada en los aislamientos mejicanos, seguido de los aislamientos de Estados Unidos y Colombia. Los análisis filogenéticos demostraron que los aislamientos VGIII están más estrechamente relacionados con el patrón VGI que con otros patrones de $C$. gattii.

Conclusión. La reciente emergencia del patrón VGIII demuestra la necesidad de expandir nuestro conocimiento de la genética y la epidemiologia de este patógeno y de relacionar la infección animal, el nicho ambiental y la enfermedad en el humano. También resalta la necesidad de determinar la posible asociación entre el genotipo y la virulencia usando modelos animales, y el análisis de la sensibilidad antifúngica.

Palabras clave: Cryptococcus gattii, vigilancia, MLST

\section{Referencias}

1. Kidd SE, Hagen F, Tscharke RL, Huynh M, Bartlett $\mathrm{KH}$, Fyfe M, et al. A rare genotype of Cryptococcus gattii caused the cryptococcosis outbreak on Vancouver Island (British Columbia, Canada). PNAS. 2004;101:17258-63.

2. Byrnes EJ 3rd, Li W, Lewit $\mathrm{Y}, \mathrm{Ma} \mathrm{H}$, Voelz K, Ren P, et al. Emergence and pathogenicity of highly virulent Cryptococcus gattii genotypes in the northwest United States. PLoS Pathog. 2010;6(4).

3. Meyer W, Aanensen DM, Boekhout T, Cogliati M, Diaz MR, Esposto MC, et al. Consensus multi-locus sequence typing scheme for Cryptococcus neoformans and Cryptococcus gattii. Med Mycol. 2009;47:561-70. 


\section{Criptococosis en niños colombianos, 1997-2010}

Jairo Lizarazo², Patricia Escandón', Clara Inés Agudelo, Elizabeth Castañeda ${ }^{1}$

1 Grupo de Microbiología, Instituto Nacional de Salud, Bogotá, D.C., Colombia

2 Hospital Universitario Erasmo Meoz, Cúcuta, Colombia

pescandon@ins.gov.co

Publicado en: Memorias, $8^{\text {th }}$ International Conference on Cryptococcus and Cryptococcosis, 1-5 de mayo de 2011, Charleston, SC, USA

Introducción. La criptococosis es menos frecuente en niños que en adultos. La vigilancia nacional de criptococosis se está realizando en Colombia desde 1997, con el objeto de proveer un estimado acerca de la situación real de esta micosis en el país.

Objetivo. Analizar los datos para el periodo 19972010 buscando información correspondiente a niños menores de 16 años.

Materiales y métodos. Se realizó un análisis retrospectivo de las encuestas registradas durante los 14 años del estudio, teniendo en cuenta datos demográficos, factores de riesgo, manifestaciones clínicas y datos de laboratorio.

Resultados. De 1.458 encuestas recibidas, se encontraron 38 casos en niños. El 60,5\% de los pacientes era de sexo masculino. La edad promedio al diagnóstico fue de 8,2 \pm 4,2 años. El paciente más joven era un neonato de 13 días, negativo para $\mathrm{VIH}$. El factor de riesgo más importante fue el $\mathrm{VIH}$ en $10(26,3 \%)$ casos, y la criptococosis definió el sida en 3 casos.

Las manifestaciones clínicas más importantes fueron: dolor de cabeza (75\%), fiebre $(71,4 \%)$, náuseas y vómito $(60,7 \%)$, alteraciones mentales (53,6 \%), signos meníngeos (39,3\%), alteraciones visuales (25\%) y tos (10,7\%).

El cultivo se reportó en 30 casos. Cryptococcus spp. fue recuperado en $93,3 \%$ de las muestras procesadas de líquido cefalorraquídeo y en 6,7\% de los hemocultivos. Cryptococcus neoformans var. grubii se identificó en $92,9 \%$ de los casos y $C$. gattii en 2 casos.

Conclusión. La vigilancia pasiva hecha a través de esta encuesta permite estimar que la criptococosis es una enfermedad poco común en niños, infectados o no por el VIH. Esta situación es similar en muchas partes del mundo con la excepción del noreste de Brasil donde la criptococosis en niños se diagnostica frecuentemente.

Palabras clave: criptococosis, niños, Colombia, vigilancia.

\section{Referencias}

1. Lizarazo J, Linares M, De Bedout C, Restrepo A, Agudelo $\mathrm{Cl}$, Castañeda E, Grupo Colombiano para el Estudio de la Criptococosis. Estudio clínico y epidemiológico de la criptococosis en Colombia: resultados de nueve años de la encuesta nacional, 1997-2005. Biomédica. 2007;27:54-64.

2. Gonzalez CE, Shetty D, Lewis LL, Mueller BU, Pizzo PA, Walsh TJ. Cryptococcosis in human immunodeficiency virus-infected children. Pediatr Infect Dis J. 1996;15:796800.

3. Darze C, Lucena R, Gomes I, Melo A. Características clínicas laboratoriais de 104 casos de meningo-encefalite criptocócica. Rev Soc Bras Med Trop. 2000;33:21-6.

Detección de Cryptococcus neoformans y Cryptococcus gattii de fuentes ambientales en Cúcuta, Colombia: ciudad con alta incidencia de casos de criptococosis por Cryptococcus gattii

Patricia Escandón ${ }^{1}$, Carolina Firacative ${ }^{1}$, Germán Torres $^{1}$, María Claudia Rodríguez ${ }^{2}$

1 Grupo de Microbiología, Instituto Nacional de Salud, Bogotá, D.C., Colombia

2 Hospital Universitario Erasmo Meoz, Cúcuta, Colombia pescandon@ins.gov.co

Publicado en: Memorias, $8^{\text {th }}$ International Conference on Cryptococcus and Cryptococcosis, 1-5 de mayo de 2011, Charleston, SC, USA

Introducción. La criptococosis por Cryptococcus gattii ocasionada por el patrón VGII prevalece en pacientes inmunocompetentes en Cúcuta. Sin embargo, este patrón no se ha recuperado del ambiente.

Objetivo. Realizar un muestreo ambiental para recuperar cepas de $C$. gattii asociados con los genotipos que infectan los pacientes.

Materiales y métodos. Se realizó un muestreo $(n=3.634)$ en enero, mayo y agosto de 2008 , en 40 zonas de la ciudad. Se tuvieron en cuenta las condiciones de temperatura, humedad relativa y precipitación. En las zonas donde se recuperó el hongo, se realizaron muestreos mensuales entre agosto de 2008 y febrero de 2009. Se 
tomaron 28 muestras de las casas de pacientes con criptococosis por C. gattii. Las muestras se procesaron por técnicas convencionales y los aislamientos se caracterizaron fenotípicamente y genotípicamente con el iniciador (GTG) $)_{5}$ y con iniciadores específicos para pareja sexual.

Resultados. Se procesaron 4.389 muestras. Se recuperaron 14 aislamientos de la variedad grubii de $3(0,07 \%)$ muestras en 2 zonas y 1 aislamiento recuperado de la casa de un paciente. Todos fueron patrón VNI, pareja sexual alfa. Veintiséis aislamientos de $C$. gattii se recuperaron de 5 (0,01 \%) muestras en 3 zonas; uno, patrón VGI, pareja sexual a; los 25 restantes, patrón VGIII, pareja sexual alfa. No hubo relación entre temperatura, condiciones climáticas y época del año para la recuperación.

Conclusión. A pesar de la baja recuperación de C. gattii, se muestra la importancia de continuar haciendo muestreos ambientales en Cúcuta donde esta especie está causando criptococosis, debido a que este patógeno ha adquirido importancia como productor de brotes. El patrón VGIII ha emergido en diferentes partes del mundo, por lo cual debemos estar en la búsqueda de su nicho ambiental.

Palabras clave: Cryptococcus, Colombia, ambiente, ecología.

\section{Referencias}

1. Firacative C, Torres G, Rodríguez MC, Escandón P. First environmental isolation of Cryptococcus gattii serotype B, from Cúcuta, Colombia. Biomédica. 2011;31(1).

2. Escandón P, Sánchez A, Martínez M, Meyer W, Castañeda E. Molecular epidemiology of clinical and environmental isolates of the Cryptococcus neoformans species complex reveals a high genetic diversity and the presence of the molecular type VGII mating type a in Colombia. FEMS Yeast Res. 2006;6:625-35.

3. Meyer W. Personal communication. 2011.

\section{La vigilancia molecular de} aislamientos del complejo Cryptococcus neoformans/ Cryptococcus gattii revela la prevalencia del patrón molecular VNI en Colombia

Patricia Escandón'1, Elizabeth Castañeda1', Wieland Meyer $^{2}$

1 Grupo de Microbiología, Instituto Nacional de Salud, Bogotá, D.C., Colombia
2 Molecular Mycology Research Laboratory, Centre for Infectious Diseases and Microbiology, Sydney Medical School-Westmead, The University of Sydney, Westmead Hospital, Westmead, NSW, Australia pescandon@ins.gov.co

Publicado en: Memorias, $8^{\text {th }}$ International Conference on Cryptococcus and Cryptococcosis, 1-5 de mayo de 2011, Charleston, SC, USA

Introducción. Los datos colombianos previos de aislamientos clínicos, recuperados entre 1993 y 2004, mostraron que 98,1 \% de los aislamientos variedad grubii pertenecían al patrón VNI y 87,5\% de C. gattii al genotipo VGII.

Objetivo. Actualizar, analizar y comparar los datos de la vigilancia molecular de la criptococosis obtenidos en el período 2003-2011.

Materiales y métodos. Se estudiaron 354 (97\%) aislamientos de $C$. neoformans y 11 (3\%) de $C$. gattii, recuperados entre 2007 y 2011, mediante PCR huella digital con el iniciador (GTG) $)_{5}$.

Resultados. Doscientos veintiún (60,6 \%) aislamientos eran de pacientes con sida; de éstos, 212 se agruparon en el patrón VNI (95,9 \%); 6 en VNII $(2,7 \%) ; 2$ en VGI (0,9\%), y 1 en VGIII (0,5\%). Ciento cuarenta y cuatro $(39,4 \%)$ aislamientos se recuperaron de pacientes sin sida, de los cuales, 133 eran VNI (92,3 \%); 3 VNII (2,1\%); 2 VGI (1,4\%), 4 VGII $(0,7 \%) ; 1$ VGIII $(0,7 \%)$ y 1 VGIV $(0,7 \%)$

Conclusión. Este estudio reafirma al patrón VNI como el más prevalente en los aislamientos de $C$. neoformans recuperados de pacientes positivos y negativos para VIH en Colombia. La criptococosis primaria causada por el patrón VGll prevalece en pacientes inmunocompetentes (2,8\%), especialmente en Cúcuta, donde la mayoría de los casos en pacientes negativos para VIH se asocian con VGII. Al comparar los datos con el periodo 1993-2004, el patrón VNI continúa siendo el más común (97,4%), y el VGll sigue siendo un genotipo importante en los aislamientos de C. gattii (36,4\%).

La vigilancia molecular es una herramienta epidemiológica importante debido a la relevancia que ha adquirido la criptococosis en los últimos años, especialmente en pacientes infectados por el VIH, no sólo en Colombia, sino a nivel mundial.

Palabras clave: criptococosis, Colombia, vigilancia, epidemiología molecular.

\section{Referencias}

1. Escandón P, Sánchez A, Martínez M, Meyer W, Castañeda E. Molecular epidemiology of clinical and environmental 
isolates of the Cryptococcus neoformans species complex reveals a high genetic diversity and the presence of the molecular type VGII mating type a in Colombia. FEMS Yeast Res. 2006;6:625-35

2. Meyer W, Castañeda A, Jackson S, Huynh M, Castañeda E; Iberoamerican Cryptococcal Study Group. Molecular typing of Iberoamerican Cryptococcus neoformans isolates. Emerg Infect Dis. 2003;9:189-95.

3. Lizarazo J, Linares M, de Bedout C, Restrepo A, Agudelo $\mathrm{Cl}$, Castañeda $\mathrm{E}$, et al. Results of nine years of the clinical and epidemiological survey on cryptococcosis in Colombia, 1997-2005. Biomédica. 2007;27:94-109.

\section{Criptococosis en Colombia: resultados del programa nacional de vigilancia, años 2006-2010}

Patricia Escandón ${ }^{1}$, Solmara Bello ${ }^{1}$, Clara Inés Agudelo1, Elizabeth Castañeda', Catalina de Bedout ${ }^{2}$, Angela Tobón², Angela Restrepo², Jairo Lizarazo ${ }^{3}$

1 Grupo de Microbiología, Instituto Nacional de Salud, Bogotá, D.C., Colombia

2 Corporación para Investigaciones Biológicas (CIB), Medellín, Colombia

3 Hospital Universitario Erasmo Meoz, Cúcuta, Colombia pescandon@ins.gov.co

Publicado en: Memorias, $8^{\text {th }}$ International Conference on Cryptococcus and Cryptococcosis, 1-5 de mayo de 2011, Charleston, SC, USA

Introducción. Desde 1997 se realiza en Colombia una encuesta nacional sobre criptococosis, para obtener un dato estimado acerca de la situación de esta micosis en nuestro país.

Objetivo. Analizar los datos obtenidos de pacientes con criptococosis para el período 2006-2010.

Materiales y métodos. Análisis retrospectivo de las encuestas recibidas.

Resultados. Se recibieron 527 encuestas procedentes de $72 \%$ de los departamentos colombianos. El $76,9 \%$ de los pacientes eran hombres y $77,7 \%$ 2tenían entre 21 y 50 años. El factor de riesgo más prevalente fue el VIH $(83,5$ $\%)$, y la criptococosis definió el sida en 29,4\% de los casos. La incidencia anual promedio en la población general fue 2,4 por $10^{6}$ individuos, y en los pacientes con sida 3,3 por $10^{3}$.

Las manifestaciones clínicas más prevalentes fueron: dolor de cabeza (84,5 \%), fiebre $(63,3 \%)$, náuseas y vómito $(57,4 \%)$, alteraciones mentales $(47,7 \%)$, signos meníngeos (33,2\%), tos (26\%) y alteraciones visuales (24,5\%). La enfermedad se clasificó en: neurocriptococosis (81,6\%), criptococosis diseminada (15,2 \%), criptococosis pulmonar $(2,8 \%)$ y criptococosis en piel $(0,2 \%)$; en 1 caso no se determinó. El examen directo en líquido cefalorraquídeo fue positivo en $96,9 \%$ de los casos, y se recuperó Cryptococcus spp. de $94,5 \%$. Cryptococcus neoformans var. grubii se recuperó en 94,6 \%; C. neoformans var. neoformans en 0,9 $\%$, y C. gattii en $2,6 \%$. Los datos anteriores señalan la importancia de la criptococosis en Colombia y la prevalencia de $C$. neoformans var. grubii como agente causal de la misma.

Conclusión. La vigilancia pasiva hecha a través de esta encuesta continúa siendo un marcador centinela para la infección por VIH en nuestro país. Constituye una aproximación sistemática al estudio de las enfermedades oportunistas que afectan especialmente a pacientes con sida, debido a que la criptococosis no es de notificación obligatoria en Colombia.

Palabras clave: criptococosis, vigilancia, sida, infección oportunista, Colombia.

\section{Referencias}

1. Lizarazo J, Linares M, De Bedout C, Restrepo A, Agudelo Cl, Castañeda E, Grupo Colombiano para el Estudio de la Criptococosis. Estudio clínico y epidemiológico de la criptococosis en Colombia: resultados de nueve años de la encuesta nacional, 1997-2005. Biomédica. 2007;27:54-64.

2. Viviani MA. Epidemiological working groups of ECMM. Mycology Newsletter. 1997;4-5.

3. Castañeda E, Torrado E, Arango M, de Bedout C, Tobón AM, Restrepo A, et al. Criptococosis en Colombia: estudio interinstitucional. Inf Quinc Epidemiol Nac. 2000;5:115-9.

\section{Caracterización parcial de los genes dihidrofolatoreductasa (dhfr) y dihidropteroatosintetasa (dhps) en aislamientos de Toxoplasma gondii}

Liliana Jazmín Cortés ${ }^{1}$, María Luz Gunturiz² ${ }^{2}$ Sofía Duque ${ }^{1}$

1 Grupo de Parasitología, Subdirección de Investigación, Instituto Nacional de Salud, Bogotá, D.C., Colombia.

2 Grupo de Fisiología Molecular, Subdirección de Investigación; Instituto Nacional de Salud, Bogotá, D.C., Colombia.

jcortes@ins.gov.co

Introducción. Toxoplasma gondii es el agente causal de lazoonosis conocida como toxoplasmosis, que se presenta como una infección asintomática en adultos sanos y con manifestaciones clínicas graves en inmunosuprimidos. El tratamiento empleado 
es clindamicina-sulfadoxina-pirimetamina, para el cual se han reportado fracasos terapéuticos asociados con mutaciones en genes blanco para estos medicamentos.

Objetivo. Estandarizar las condiciones de amplificación por PCR del exón 2 del gen dhfr y los exones $1 \mathrm{ab}, 2,4$ y 5 del gen dhps a partir de la cepa de referencia $\mathrm{RH}$ y de dos aislamientos de $T$. gondii obtenidos de pacientes positivos para $\mathrm{VIH}$ con toxoplasmosis cerebral.

Materiales y métodos. Se realizaron las PCR a partir de 100 ng de ADN genómico. Se realizó la secuenciación directa con los productos purificados, empleando los iniciadores de PCR para cada uno de los exones. Las secuencias obtenidas fueron comparadas con las secuencias disponibles en Refseq (NCBI).

Resultados. Se estandarizaron las condiciones de amplificación del exón 2 del gen dhfr y de los exones 1ab, 2, 4 y 5 del gen dhps y se encontró que las secuencias obtenidas para estos exones eran idénticas a las reportadas en las bases de datos mundiales. Sin embargo, se encontró un cambio de un nucleótido para el exón 2 del gen dhps en las tres muestras secuenciadas.
Conclusión. La estandarización de las condiciones para la amplificación por PCR de los genes dhps y dhfr permitirá realizar estudios de polimorfismo y establecer su posible asociación con resistencia a medicamentos en muestras de pacientes con diferentes manifestaciones clínicas de toxoplasmosis.

Palabras clave: toxoplasmosis, dihidrofolatoreductasa, dihidropteroatosintetasa, resistencia a medicamentos, Toxoplasma gondii

\section{Referencias}

1. Aspinall TV, Joynson DH, Guy E, Hyde JE, Sims PF. The molecular basis of sulfonamide resistance in Toxoplasma gondii and implications for the clinical management of toxoplasmosis. J Infect Dis. 2002;185:1637-43.

2. Gómez J, Alvarado F, Hernández C, Cuervo S, Saravia J. Tratamiento de la fase aguda de la toxoplasmosis cerebral con Clindamicina-Falcidar (pirimetamina-sulfadoxina) en pacientes infectados por VIH. Infectio. 2001; 5:163-9.

3. Reynolds $\mathrm{M}$, Jung $\mathrm{O}$, David S. In vitro generation of novel pyrimethamine resistance mutations in the Toxoplasma gondii dihydrofolate reductase. Antimicrob Agents Chemother. 2001;45:271-7. 


\section{ENFERMEDADES ZOONÓTICAS Y DESATENDIDAS}

\author{
Estudio inmunohistoquímico \\ de la expresión de calbindina y \\ parvoalbúmina en la médula espinal de \\ ratones \\ Jeison Monroy-Gómez ${ }^{1,2}$, Orlando Torres-Fernández² \\ 1 Universidad del Tolima, Ibagué, Colombia \\ 2 Grupo de Morfología Celular, Subdirección de \\ Investigación, Instituto Nacional de Salud, Bogotá, \\ D.C., Colombia \\ otorresf@ins.gov.co
}

Introducción. La calbindina y la parvoalbúmina son proteínas que contribuyen a regular la concentración intracelular de calcio. Estas proteínas se distribuyen selectivamente en diferentes tipos de neuronas y, por esta razón, se utilizan como marcadores para caracterizar poblaciones neuronales en condiciones normales y patológicas. Hasta donde tenemos conocimiento, no se han reportado estudios previos sobre la presencia de estas proteínas en la médula espinal del ratón.

Objetivo. Establecer el patrón de distribución calbindina y parvoalbúmina en diferentes regiones de la médula espinal de ratones.

Materiales y métodos. Se anestesiaron ratones ICR, se fijaron por perfusión intracardiaca con paraformaldehído y se les extrajo la médula espinal. En un vibrátomo se obtuvieron cortes transversales de $50 \mu \mathrm{m}$ de espesor y se procesaron mediante técnica inmunohistoquímica utilizando anticuerpos anti-calbandina y anti-parvoalbúmina.

Resultados. Siguiendo la estratificación de Rexed para la sustancia gris de la médula espinal, se encontraron células positivas para calbandina en las láminas I y II, en menor proporción en la lámina IX y, ocasionalmente, en la lámina III. Las células positivas para parvoalbúmina se distribuyeron principalmente en las láminas III y IV y en menor proporción, en las láminas I y II. También se debe destacar que en el asta anterior la inmunorreactividad para parvoalbúmina fue mayor que para calbindina.

Conclusión. La distribución de calbindina y parvoalbúmina hallada en la médula espinal de ratón conserva el patrón básico descrito para otros mamíferos pero exhibe algunas diferencias puntuales, inclusive, con la médula espinal de ratas, especialmente en la expresión de PV de las láminas I y II.
Palabras clave: ion calcio, calbindina, parvoalbúmina, médula espinal, inmunohistoquímica.

\section{Referencias}

1. Baimbridge K, Celio M, Rogers J. Calcium-binding proteins in the nervous system. Trends Neurosci. 1992;15:303-8.

2. Torres-Fernández $\mathrm{O}$, Yepes GE, Gómez JH, Pimienta $\mathrm{HJ}$. Efecto de la infección por el virus de la rabia sobre la expresión de parvoalbúmina, calbindina y calretinina en la corteza cerebral de ratones. Biomédica. 2004;24:63-78.

3. Torres-Fernández $\mathrm{O}$, Yepes GE, Gómez JH, Pimienta HJ. Calbindin distribution in cortical and subcortical brain structures of normal and rabies infected mice. Int J Neurosci. 2005;115:1372-85.

4. Ren K, Ruda M. A comparative study of the calcium-binding proteins calbindin, calretinin, calmodulin and parvalbumin in the rat spinal cord. Brain Res Review. 1994;19:163-79.

5. Anelli R, Heckman CJ. The calcium binding proteins calbindin, parvalbumin, and calretinin have specific patterns of expression in the gray matter of cat spinal cord. J Neurocytol. 2005; 34:369-85.

\section{Rickettsiosis: informe de un caso}

Solmara Bello, Flor Rodríguez, María Elena Realpe

Grupo de Microbiología, Subdirección Red Nacional de Laboratorios, Instituto Nacional de Salud, Bogotá, D.C., Colombia

sbello@ins.gov.co

Presentado en: III Congreso Latinoamericano de Enfermedades Rickettsiales y I Encuentro Nacional de Fiebres Hemorrágicas, Bogotá, 6-8 de julio de 2011.

Introducción. La fiebre manchada es producida por Rickettsia rickettsii, transmitida por medio de garrapatas. En Colombia se ha reportado la presencia de rickettsiosis en diferentes municipios (Villeta, Ciénaga de Oro, Urabá, Necoclí, etc.), sin embargo, la situación real de la enfermedad es desconocida en gran parte del territorio nacional, debido a la difícil diferenciación clínica entre la rickettsiosis y otras enfermedades febriles agudas durante los primeros días de inicio de la enfermedad.

Objetivo. Diagnosticar un posible caso de rickettsiosis.

Materiales y métodos. Reportamos el caso clínico de un niño de 12 años procedente de Mariquita, Tolima, con el antecedente de haber estado en una finca cafetera ubicada en un municipio de Santander, donde tuvo contacto con ganado. Acudió el 4 enero de 2011 al centro de salud con cuadro 
febril agudo de 18 días de evolución, malestar general, astenia, fiebre de $40{ }^{\circ} \mathrm{C}$, cefalea y dolor toráxico. El paciente fue tratado con ceftriazona 2 $\mathrm{g}$ al día por 14 días.

Fue hospitalizado el 15 enero de 2011 en la unidad de cuidados intensivos por choque compensado, dolor abdominal, muscular y de tórax, y aparición de petequias en los miembros inferiores asociadas a hemorragias. Se se le ordenó cuadro hemático, determinación de transaminasas y pruebas para el diagnóstico de síndromes febriles.

Resultados. En el cuadro hemático se observó presencia de anemia leve y trombocitopenia; las transaminasas estaban elevadas; la prueba de inmunofluorescencia indirecta IgM para $R$. rickettsii presentó títulos mayores de 1:1.040 tanto en la primera como en la segunda muestra, e IgG con títulos de 1:128 para la primera y 1:256 para la segunda muestra, la prueba de microaglutinación para Leptospira spp. mostró un resultado de $L$. australis 1:100 en la primera y la segunda, lo cual sugería la presencia de anticuerpos de memoria; la prueba para dengue tuvo resultados negativos.

El paciente respondió adecuadamente al tratamiento con dipirona, acetaminofén, lactato de Ringer y doxiciclina.
Conclusión. El paciente se diagnosticó con rickettsiosis por R.rickettsii. La fiebre manchada se debe considerar entre los síndromes febriles ictéricos por los médicos clínicos, en población expuesta a garrapatas y considerarse como una enfermedad emergente con alta letalidad.

Palabras clave: fiebre manchada, Rickettsia rickettsii, garrapatas.

\section{Referencias}

1. Chapman AS, et al. Diagnosis and management of tickborne rickettsial diseases: Rocky Mountain spotted fever, erlichioses, and anaplasmosis-United States: a practical guide for physicians and other health-care and public health professionals. MMWR Recomm Rep. 2006;55:1-27.

2. Hidalgo $\mathrm{M}$, et al. Detección de anticuerpos contra arbovirus y rickettsias en sueros provenientes del programa centinela de entidades febriles, 2000-2004. Inf Quinc Epidemiol Nac. 2007;12:81-96.

3. Acosta J, et al. Brote de rickettsiosis en Necoclí, Antioquia, febrero-marzo de 2006. Inf Quinc Epidemiol Nac. 2006;11:177-92. 


\section{DESARROLLO E IMPLEMENTACIÓN DE METODOLOGÍAS DIAGNÓSTICAS}

\section{Disociación celular para obtener células progenitoras de melanocitos a partir de piel}

\author{
Esteban Camilo Rodríguez, Luis Alberto Gómez \\ Grupo de Fisiología Molecular, Subdirección de \\ Investigación, Instituto Nacional de Salud, Bogotá, D.C., \\ Colombia \\ Igomez@ins.gov.co
}

Introducción. El melanoma es de los tumores sólidos más malignos, con tasas de mortalidad elevadas. La fisiopatología celular y molecular de este cáncer aún no se conoce totalmente y se describe una alta heterogeneidad celular. Por esta razón, actualmente se pretende asociar al melanoma con teorías de carcinogénesis que incluyen la evolución clonal y su potencial origen en células madre o células progenitoras de origen melanocítico. Este conocimiento contribuirá a identificar las células diana del proceso de carcinogénesis y progresión tumoral en el cáncer de piel más maligno.

Objetivo. Estandarizar un método de disociación celular para aislar potenciales células madre de folículos pilosos de piel completa.

Materiales y métodos. Segmentos de $2 \mathrm{~mm}^{2}$ de piel de cobayo fueron sometidos a digestión enzimática durante una hora a $37^{\circ} \mathrm{C}$, con diferentes concentraciones de colagenasa-EDTA. Con el fin de obtener un cultivo homogéneo de células con características fenotípicas específicas, se aislaron y fragmentaron folículos pilosos mediante microdisección, empleando tripsina-EDTA de 5 a 10 minutos a $37^{\circ} \mathrm{C}$ en intervalos de 1 minuto.

Resultados. El tratamiento de piel completa con colagenasa-EDTA $(5 \mathrm{mg} / \mathrm{ml}$ y $5 \mathrm{mM}, 1$ hora a 37 @C, respectivamente) permitió una adecuada disociación entre dermis y epidermis, y la obtención de folículos pilosos, y promovió la disgregación de las células, sin daños celulares aparentes. Además, se logró el aislamiento de un tipo celular de morfología similar al de células madre de linaje melanocítico.

Conclusión. La disociación enzimática con colagenasa-EDTA a concentraciones y condiciones experimentales controladas, favorece la disociación de tejido epitelial, para cultivos primarios como fase preliminar al aislamiento y caracterización de células madre de origen melanocítico. El estudio de células progenitoras de melanocitos permitirá realizar estudios de diferenciación, transformación celular y comparación con las células tumorales, para desarrollar estrategias de prevención, diagnóstico y de terapia más eficaces.

Palabras clave: melanocitos, melanoma, colagenasa, diferenciación, células madre.

\section{Referencias}

1. Kyrgidis A, Tzellos TG, Triaridis S. Melanoma: Stem cells, sun exposure and hallmarks for carcinogenesis, molecular concepts and future clinical implications. J Carcinog. 2010;9:3.

2. Vultur A, Herlyn M. Cracking the system: Melanoma complexity demands new therapeutic approaches. Pig Cell Mel Res. 2009;22:4-5.

3. Quintana E, Shackleton M, Foster HR, Fullen DR, Sabel MS, Johnson TM, et al. Phenotypic heterogeneity among tumorigenic melanoma cells from patients that Is reversible and not hierarchically organized. Cancer Cell. 2010;18:51023.

4. Civenni G, Walter A, Kobert N, Mihic-Probost D, Zipser M, Belloni B, et al. Human CD271-positive melanoma stem cells associated with metastasis establish tumor heterogeneity and long-term growth. Cancer Research. 2011;71:3098-109.

\section{Determinación de hemoglobinopatías en muestras de sangre seca de cordón umbilical}

María Jimena Rosero, Antonio José Bermúdez

Grupo de Genética, Subdirección Red nacional de Laboratorios, Instituto Nacional de Salud, Bogotá, D.C., Colombia

mjrosero@ins.gov.co

Introducción. Las hemoglobinopatías son consecuencia de mutaciones con repercusión estructural en las cadenas de globina, causando así enfermedades por deformación de los eritrocitos. Inicialmente endémicas en África ahora son un problema de salud pública en diferentes regiones del mundo por la migración, la diversidad étnica y la heterogeneidad en la distribución de las poblaciones.

El presente estudio está orientado a documentar los trastornos de hemoglobina en recién nacidos de diferentes áreas geográficas del país, con alta proporción de población afro-colombiana, utilizando la plataforma de tamización neonatal existente para la recolección de muestras de sangre seca de cordón umbilical. 
Objetivo. Determinar las variantes de hemoglobina en muestras de sangre seca de recién nacidos.

Materiales y métodos. Se recibieron 4.196 muestras de sangre seca de cordón umbilical, recolectadas en tarjetas de papel de filtro Whatman grado 903, enviadas por los laboratorios departamentales de salud pública de Chocó, La Guajira, San Andrés y Providencia, Nariño y Putumayo.

De las muestras recibidas, 1.160 se analizaron con la técnica de isoelectroenfoque y 1.820 por electroforesis capilar; los análisis se hicieron con las dos metodologías para los casos positivos.

Resultados. Se analizaron 2.356 muestras, de las cuales se obtuvieron 2.209 patrones electroforéticos normales $(93,3 \%)$ y 147 anormales (6,7\%). Se identificó un caso homocigoto para hemoglobina S, 97 casos heterocigotos para hemoglobina S, 43 casos heterocigotos para hemoglobina $C, 5$ casos de hemoglobina de Bart y un caso doble heterocigoto de hemoglobina S/C.

Conclusión. Los resultados obtenidos en este estudio aportan evidencia de la necesidad de desarrollar una política nacional para la implementación de la tamización neonatal de las hemoglobinopatías en Colombia, que permita identificar portadores y plantear estrategias de prevención y manejo encaminadas a reducir las tasas de morbilidad y la mortalidad por este evento de interés en salud pública, que afecta primordialmente población afrodescendiente.

Palabras clave: hemoglobinopatías, isoelectroenfoque, electroforesis capilar, homocigoto, heterocigoto.

\section{Referencias}

1. Bull World Health Org. 2008;86:480-7.

2. Management of haemoglobin Disorders. World Health Organization, Nicosia, Cyprus, November 16-18, 2007

3. Implementation of universal newborn blood spot screening for sickle cell disease and other clinically significant haemoglobinopathies in England: screening results for 2005-7. J Clin Pathol. 2009;62:26-30.

\section{Tuberculosis extrapulmonar, diagnóstico por PCR IS6110}

Maira Wintaco ${ }^{1}$, Gloria Puerto ${ }^{1}$, Martha Inírida Guerrero ${ }^{1,2}$

Grupo de Micobacterias, ' Subdirección de Investigación y ${ }^{2}$ Subdirección Red Nacional de Laboratorios, Instituto Nacional de Salud, Bogotá, D.C., Colombia

gpuerto@ins.gov.co
Introducción. La Organización Mundial de la Salud estimó 0,9 millones de casos de tuberculosis extrapulmonar en el mundo en 2009. Aunque esta enfermedad se presenta con menor frecuencia que la tuberculosis pulmonar, su incidencia viene en aumento, principalmente en grupos de riesgo como las personas con inmunosupresión. IS6110 es una secuencia de inserción presente exclusivamente en los miembros del complejo Mycobacterium tuberculosis, que puede ser una herramienta útil en la detección de las micobacterias del complejo.

Objetivo. Identificar micobacterias del complejo $M$. tuberculosis mediante la PCR IS6110, en muestras clínicas de pacientes con sospecha clínica de tuberculosis extrapulmonar.

Materiales y métodos. Doce hospitales de diferentes departamentos del país, remitieron 19 muestras de aspirado ganglionar, biopsia de pulmón, lavado broncoalveolar, liquido cefalorraquídeo, liquido pleural u orina, entre agosto de 2010 y mayo de 2011, Las muestras se analizarons por PCR y los productos de amplificación se visualizaron por electroforesis para determinar la presencia 0 ausencia de ADN perteneciente a algún miembro del complejo M. tuberculosis.

Resultados. Diez $(52,63 \%)$ muestras pertenecían a hombres entre 43 a 85 años y $9(47,36 \%)$ a mujeres entre 30 y 81 años; en la historia clínica de un paciente, se reportó que era positivo para VIH. El porcentaje de resultados positivos para IS6110 fue de 52,63\%, 10 muestras amplificadas y $9(47,36 \%)$ muestras negativas.

Conclusión. Se pudo evidenciar la presencia de ADN perteneciente al complejo $M$. tuberculosis, con una metodología rápida y económica que puede ser aplicada de rutina en los laboratorios de diagnostico para evidenciar tuberculosis.

Palabras clave: tuberculosis extrapulmonar, diagnóstico, PCR, tuberculosis

\section{Referencias}

1. World Health Organization. MDR-TB and XDR-TB. WHO Report 2011. Geneve: WHO; 2011.

2. van Soolingen D, Hermans PW, de Haas PE, Soll DR, van Embden JD. The occurrence and stability of insertion sequences in Mycobacterium tuberculosis complex strains; evaluation of IS-dependent DNA polymorphism as a tool in the epidemiology of tuberculosis. J Clin Microbiol. 1991;29:2578-86. 


\section{Micobacterias en pacientes positivos para VIH de tres hospitales de Bogotá}

Luz Farley Córdoba', Lina Erazo', Fabiola Chinchilla², Maira Wintaco ${ }^{3}$, Gloria Puerto ${ }^{3}$, Martha Inírida Guerrero ${ }^{3}$

1 Universidad Colegio Mayor de Cundinamarca, Bogotá, D.C., Colombia

2 Hospital Simón Bolívar, Bogotá, D.C., Colombia

3 Grupo de Micobacterias, Subdirección de Investigación, Instituto Nacional de Salud, Bogotá, D.C., Colombia gpuerto@ins.gov.co

Introducción. La Organización Mundial de la Salud estimó en 2009 entre 1 y 1,2 millones de pacientes positivo para VIH con tuberculosis, de los cuales, 0,4 millones murieron. Las micobacterias no tuberculosas, especialmente las del complejo Mycobacterium avium, también afectan estos pacientes.

Objetivo. Aislar micobacterias causantes de enfermedad en pacientes portadores del VIH en los hospitales San Ignacio y Simón Bolívar y en la Clínica Jorge Piñeros Corpas de Bogotá.

Materiales y métodos. Se recolectaron 30 muestras de sangre, esputo, materia fecal, líquido cefalorraquídeo, biopsia de ganglio y lavado bronquial, provenientes de 27 pacientes positivos para VIH de tres hospitales de Bogotá. Se determinaron las características demográficas de los pacientes y las muestras se sometieron a investigación microbiológica y molecular para micobacterias empleando las metodologías convencionales, PCR-IS6110 y spoligotyping. La secuenciación de la región ITS del rARN 16S fue hecha en el Grupo de Fisiología Molecular del Instituto Nacional de Salud.

Resultados. Ochenta y nueve por ciento de los pacientes fueron hombres, $52 \%$ de ellos estuvoen el rango de los 26 a los 41 años y todos los pacientes estaban hospitalizados en fase sida. Por cultivo se detectaron 5 pacientes con $M$. tuberculosis, 1 paciente con $M$. avium y 2 pacientes con Mycobacterium sp. Las pruebas moleculares identificaron $M$. tuberculosis en 28 muestras (93,3 \%), la presencia de M. avium se corroboró por secuenciación y a este mismo paciente se le confirmó $M$. tuberculosis.

Conclusiones. Se pudo evidenciar la presencia de $M$. tuberculosisy M. aviumen las muestras analizadas. Un paciente presentó infección mixta, y se confirmó que las pruebas moleculares incrementan la sensibilidad de detección de micobacterias comparado con las pruebas microbiológicas.
Palabras clave: Mycobacterium tuberculosis, $\mathrm{VIH}$, tuberculosis, coinfección VIH-TB.

\section{Referencias}

1. World Health Organization. Global tuberculosis control. WHO Report 2009. Geneve: WHO; 2009.

2. Kox F van Leeuwen J, Knijper S, Jansen HM, Kolk HJ. PCR assay based on DNA coding for 16s rRNA for detection and identification of Mycobacteria in clinical samples. J Clin Microbiol. 1995;33:3225-33.

3. Murcia MI, Gómez JE, Alvarado FS, Bustillo JG, De Mendivelson E, Gómez B, León Cl. Frequency of tuberculous and non-tuberculous mycobacteria in HIV infected patients from Bogota, Colombia. BMC Infect Dis. 2001;1:21.

\section{Evaluación del rendimiento de una prueba rápida de diagnóstico para la enfermedad de Chagas y estimación de la seroprevalencia en escolares de una zona endémica de Colombia}

Carolina Flórez1, Lorena González², Lesly Guasmayán1, Paola Peña ${ }^{1}$, Zulma Cucunubá ${ }^{1}$, Nubia Silva ${ }^{3}$, Mónica Calderón ${ }^{3}$, Liliana Mogollón ${ }^{3}$, Marleny Montilla', Felipe Guhl²

1 Grupo de Parasitología, Instituto Nacional de Salud, Bogotá, D.C., Colombia

2 Centro de Investigaciones en Microbiología y Parasitología Tropical, Universidad de los Andes, Bogotá, D.C., Colombia

3 Servinsalud Ltda., Yopal, Colombia aflorez@ins.gov.co

Presentado en: XLV Congreso de Ciencias Biológicas, octubre de 2010, Armenia

Introducción. La confiabilidad de los resultados en la tamización serológica para detectar la infección por Trypanosoma cruzi es primordial como herramienta de diagnóstico y como indicador de las acciones de control.

Objetivo. Comparar la prueba rápida Chagas Xerion® y la prueba ELISA en papel filtro y evaluar el rendimiento de estas dos pruebas de tamización como parámetro de confirmación serológica, para determinar la seroprevalencia de la enfermedad de Chagas en niños de 5 a 18 años en Nunchía (Casanare).

Materiales y métodos. Se tamizaron 1.898 muestras de sangre mediante las técnicas ELISA y Xerion®. Las muestras positivas se confirmaron en suero por ELISA e inmunofluorescencia indirecta (IFI) o hemaglutinación indirecta (HAI). 
Resultados. Los resultados concordantes entre las pruebas evaluadas arrojaron una seroprevalencia de 2,16\% ( $\left.\mathrm{IC}_{95 \%} 1,55-2,91\right)$. El índice kappaentre Chagas Xerion® y ELISA fue de 0,47 (IC ${ }_{95 \%} 0,35-$ 0,58 ) con sensibilidad y especificidad de $46,7 \%$ y $98 \%$, respectivamente. Frente a la seropositividad por dos técnicas de principio diferente la prueba Xerion $\AA$ mostró sensibilidad de $85 \%$ y especificidad de $98 \%$ y la ELISA una sensibilidad y especificidad de $93 \%$ y $98 \%$, respectivamente.

Conclusión. La prueba ELISA de tamización en papel filtro presentó la mayor sensibilidad y especificidad comparada con la prueba Xerion ${ }^{\circledR}$ que mostró una buena especificidad, pero baja sensibilidad. Las pruebas rápidas constituyen una buena alternativa para tamización a futuro, siempre y cuando se realicen previamente los controles de calidad y validación respectiva.

Palabras clave: Enfermedad de Chagas, tamización serológica, Nunchía (Casanare).

\section{Referencias}

1. OPS. Manual de manejo de enfermedades parasitarias prioritarias en Honduras. Segunda edición. Tegucigalpa: Instituto de Enfermedades infecciosas y Parasitología Antonio Vidal; 2009.

2. Orozco LC, Camargo D, López MC, Duque S, Gualdron LE, Cáceres E, Ronderos $M$, Rey $M$, Corredor $A$. Inmunodiagnóstico de la infección chagásica por Trypanosoma cruzi mediante ELISA utilizando sangre recolectada en papel filtro. Biomedica. 1999;19:164-7.

3. Roddy P, Goiri J, Flevaud L, Palma PP, Morote S, Lima N, et al. Field evaluation of a rapid immunochromatographic assay for detection of Trypanosoma cruzi infection by use of whole blood. J Clin Microbiol. 2008;46:2022-7.

\section{Estandarización del método de xeno- diagnóstico artificial para confirmación de infección por Trypanosoma cruzi y el seguimiento postratamiento etiológico de la enfermedad de Chagas}

Marleny Montilla ${ }^{1}$, Tania Tibaduiza², Zulma Cucunubá1, Jaime Ramírez ${ }^{2}$, Mariela Torres ${ }^{2}$, Edgar Parra ${ }^{3}$

1 Grupo de Parasitología, Subdirección de Investigación, Instituto Nacional de Salud, Bogotá, D.C., Colombia

2 Grupo de Entomología, Subdirección de Investigación y Red Nacional de Laboratorios, Instituto Nacional de Salud, Bogotá, D.C., Colombia

3. Grupo de Patología, Subdirección de Red Nacional de Laboratorios, Instituto Nacional de Salud, Bogotá, D.C., Colombia mmontilla@ins.gov.co
Presentado en: XIV Congreso Nacional de Ciencias Biológicas. octubre 2010, Armenia

|Introducción. El xenodiagnóstico artificial es una herramienta para confirmar el diagnóstico de infección por Trypanosoma cruzi, y puede ser útil para el seguimiento postratamiento.

Objetivo. Estandarizar la metodología del xenodiagnóstico artificial como herramienta alternativa de confirmación de la infección por T. cruzi, e incluirla dentro del protocolo de la enfermedad de Chagas implementado en el Instituto Nacional de Salud

Metodología. De cuatro pacientes con diagnóstico de enfermedad de Chagas por pruebas serológicas (1 caso agudo, 2 casos posteriores a trasplante y 1 caso crónico) se obtuvieron muestras de sangre venosa, después del tratamiento con benznidazol (Rochagán $\AA^{\circledR}$ ). Siete a ocho ninfas de Rhodnius prolixus de tercer estadio fueron alimentadas con alimentador y membrana de látex. Como control positivo se utilizó sangre de ratón ICR infectado con T. cruzi MHOM/CO/01/DA, la cual fue mezclada con sangre humana para obtener diluciones $1 \times 10^{5}, 10^{4}$ y $10^{3}$, con mediciones de la parasitemia realizadas en cámara de recuento celular. Las lecturas de las deyecciones de los insectos se hicieron en los días 30, 60 y 90 posteriores a la alimentación.

Resultados. Ninguno de los insectos alimentados con sangre de pacientes presentó parásitos. Por el contrario, en las deyecciones de los insectos alimentados con sangre de ratón infectado se observaron parásitos hasta los14 días después de la infección.

Conclusión. El xenodiagnóstico artificial requiere de concentraciones parasitarias relativamente altas para lograr resultados positivos. A pesar de que la sensibilidad de la prueba no es alta, especialmente en fase crónica, los resultados positivos indican indudablemente la necesidad de tratamiento etiológico, por lo tanto, puede ser útil para el seguimiento postratamiento.

Palabras clave: enfermedad de Chagas, tratamiento etiológico, Rhodnius prolixus, xenodiagnóstico artificial.

\section{Referencias}

1. Pinto AY, Ferreira A Jr., Valente V, Harada G, Valente $S$. Urban outbreak of acute Chagas disease in Amazon región of Brazil: Four-year follow-up after treatment with benznidazole. Rev Panam. Salud Pública.), 2009;25:77-83.

2. Portela-Lindoso AA, Shikanai-Yasuda MA. Doença de Chagas crónica: xenodiagnóstico e hemocultura a reaçao 
en cadeia da polimerase.. Rev Saude Pública. 2003;37: 107-15.

3. Dos Santos AH, da Silva IG, Rassi A. Un estudio comparativo entre xenodiagnóstico natural y artificial en los pacientes crónicos de la enfermedad de Chagas. Soc Bras Rev Med Trop. 1995;28:367-73.

\section{Establecimiento y caracterización de una línea celular derivada de Culex quinquefasciatus, Say 1828 (Diptera: Culicidae)}

Alexandra Segura', Erika Santamaría ${ }^{2}$, Olga Lucía Cabrera $^{2}$, Felio Bello ${ }^{1}$

1 Laboratorio de Entomología Médica y Forense, Facultad de Ciencias Naturales y Matemáticas, Universidad del Rosario, Bogotá, D.C., Colombia

2 Grupo de Entomología, Subdirección de Investigación, Instituto Nacional de Salud, Bogotá, D.C., Colombia esantamaria@ins.gov.co

Introducción. EnColombia, Culexquinquefasciatus es una especie frecuente en diversas áreas urbanas y rurales y su importancia radica en la molestia sanitaria causada a las personas por sus picaduras. Por otra parte, el establecimiento de cultivos celulares de insectos, en especial de mosquitos con relevancia en salud pública como $C$. quinquefasciatus, se constituye en una herramienta útil en estudios básicos y aplicados.

Objetivo. Establecer y caracterizar una nueva línea celular derivada de tejidos embrionarios de C. quinquefasciatus.

Materiales y métodos. Se tomaron huevos "embrionados" de C. quinquefasciatus, como fuente de tejido para realizar los explantes que fueron sembrados en medios de cultivo L-15, Grace, Grace/L-15, MM/VP12, Schneider y DMEM. Se efectuó la caracterización morfológica, citogenética, bioquímica y molecular de los cultivos celulares, mediante la definición de formas celulares, obtención del cariotipo, técnica de electroforesis y RAPD-PCR, respectivamente.

Resultados. El medio Grace/L-15 brindó condiciones nutritivas óptimas para la adhesión y proliferación celular. Después de 40 a 60 días de realizados los explantes, se obtuvo una monocapa confluente con morfologías celulares heterogéneas en los cultivos primarios y subcultivos, en donde predominaron las formas epitelioides. Se estableció el cariotipo de los cultivos celulares con un número diploide de 6. Los patrones isoenzimáticos y moleculares de los cultivos celulares del mosquito coincidieron con los obtenidos de las formas inmaduras y adultas de la misma especie. Se han registrado en el proceso de desarrollo de la línea celular 18 subcultivos sucesivos.

Conclusión. Se estableció y caracterizó una nueva línea celular derivada de tejidos embrionarios de $C$. quinquefasciatus, la cual tendrá diferentes aplicaciones biomédicas, principalmente en estudios de susceptibilidad a infecciones con arbovirus y parásitos.

Palabras clave: Culex quinquefasciatus, línea celular, tejidos embrionarios, medios de cultivo, cariotipo.

\section{Referencias}

1. Ardila A, Escovar J, Bello FJ. Características de nuevos cultivos celulares derivados de tejidos embrionarios de Aedes aegypti (Diptera: Culicidae). Biomédica. 2005;25:6575.

2. Bello FJ, Brochero H, Boshell J, Olano V, Rey G. Establishment and characterization of a cell line from mosquito Anopheles albimanus (Diptera: Culicidae). Mem Inst Oswaldo Cruz. 1997;92:123-8.

3. Salazar M, Moncada L. Ciclo de vida de Culex quinquefasciatus Say 1826 (Diptera: Culicidae) bajo condiciones no controladas en Bogotá. Biomédica. 2004;24:385-92.

\section{Producción de anticuerpos policlonales a partir de proteínas recombinantes de Plasmodium falciparum}

Samanda Aponte ${ }^{1}$, Jacqueline Chaparro ${ }^{2}$

${ }^{1}$ Grupo de Bioquímica, Subdirección de Investigación, Instituto Nacional de Salud, Bogotá, D.C., Colombia

2 Universidad El Bosque, Laboratorio de Parasitología Molecular, Bogotá, D.C., Colombia

saponte@ins.gov.co

Introducción. Dos de las herramientas moleculares más usadas para descubrir antígenos y posibles blancos farmacológicos en el proteoma de Plasmodium falciparum, son las proteínas recombinantes y los anticuerpos policlonales producidos a partir de ellas. Este acercamiento experimental se usó para estudiar a PfMyoC, una proteína que ha despertado gran interés por ser la única miosina del parásito que no ha sido caracterizada.

Objetivo. Obtener una proteína recombinante de PfMyoC (rPfMyoC) en un sistema procariota y producir con ella un anticuerpo policlonal. 
Materiales y métodos. Se estandarizó la producción de rPfMyoC usando el sistema de expresión pET y se ensayaron diferentes protocolos para recuperarla desde los cuerpos de inclusión. Luego, se purificó rPfMyoC y se empleó como antígeno para inocular ratones Balb C.

Resultados. La proteína rPfmyoC fue exitosamente expresada a las dos horas después de la inducción, pero de forma insoluble. La mejor estrategia para recuperarla de los cuerpos de inclusión fue el tratamiento con guanidina- $\mathrm{HCl}$ durante 1 hora. La purificación se logró por cromatografía de afinidad seguida de SDS-PAGE y extracción a partir del gel.

Finalmente, se obtuvieron tres anticuerpos policlo-nales que reconocieron específicamente a rPfmyo-C en lisados de cultivos bacterianos y a $\mathrm{PfMyoC}$ en lisados de parásitos intraeritrocitarios en diferentes concentraciones del anticuerpo. No se observó señal sobre lisados de bacterias transformadas con vector sin inserto, ni usando sueros preinmune.

Conclusión. La estrategia empleada para la producción de los anticuerpos policlonales contra rPfmyo-C fue exitosa, permitiendo el reconocimiento de la proteína Pfmyo-C de $P$. falciparum lo cual es esencial para el estudio de expresión y localización de la proteína durante el ciclo intraeritrocitario del parásito.

Palabras clave: Plasmodium falciparum, proteínas recombinantes, anticuerpos policlonales.

\section{Referencias}

1. Coligan J, Dunn B, et al., editors. Short protocols in protein science: a compendium of methods from current protocols in protein science. USA: Wiley; 2003.

2. Novagen. pET System Manual. Eleventh edition: 2006. p. 1-80.

3. Scheer JM, Ryan CA. A method for the quantitative recovery of proteins from polyacrylamide gels. Anal Biochem. 2001;298:130-2.

\section{Detección de antígenos de influenza A en tejido pulmonar mediante un método inmunohistoquímico}

Jorge Rivera ${ }^{1}$, Marcela Neira², Ladys Sarmiento ${ }^{3}$, Edgar Parra $^{2}$, María Leonor Caldas ${ }^{3}$

1 Joven investigador, Grupo de Morfología Celular, Subdirección de Investigación, Instituto Nacional de Salud, Bogotá, D.C., Colombia
2 Grupo de Patología, Subdirección de la Red Nacional de Laboratorios, Instituto Nacional de Salud, Bogotá, D.C., Colombia

3 Grupo de Morfología Celular, Subdirección de Investigación, Instituto Nacional de Salud, Bogotá, D.C., Colombia mcaldas@ins.gov.co

Introducción. La influenza es una enfermedad respiratoria aguda que se presenta de forma estacional y pandémica, y representa uno de los mayores riesgos en salud pública.

Objetivo. Detectar mediante un método inmunohistoquímico los antígenos del virus de influenza de tipo A en células infectadas de tejido pulmonar.

Materiales y métodos. Veinte muestras de tejido pulmonar incluido en parafina con diagnóstico por RT-PCR para el virus de influenza A H1N1/v09 fueron estudiados mediante inmunohistoquímica con el método de estreptavidina-fosfatasa alcalina.

Resultados. De las 20 muestras de tejido pulmonar estudiadas, $70 \%$ presentaba un diagnóstico histopatológico de neumonitis aguda exudativa fibrinoide y $30 \%$ de alveolitis aguda necrosante. El $90 \%$ de las muestras presentó inmunoreactividad en el epitelio bronquiolar y en células del infiltrado de la luz alveolar. El antígeno viral se localizó principalmente en el citoplasma de las células epiteliales del bronquíolo, disminuyendo su presencia en células del epitelio alveolar.

Se presentó inespecificidad de la inmunoreacción con otros métodos de inmunohistoquímica evaluados, la cual fue eliminada al usar ácido acético glacial como agente de bloqueo para la fosfatasa alcalina endógena.

La sensibilidad del método de inmunohistoquímica con un intervalo de confianza del $95 \%$ fue del $90 \%$.

Conclusión. El método de estreptavidina-fosfatasa alcalina es una herramienta conveniente para la detección de antígenos virales en tejidos incluidos en parafina y constituye una aproximación técnica para el estudio básico de las alteraciones morfológicas asociadas a la infección por el virus de la influenza A H1N1, y contribuye a resolver preguntas sobre una patología que aun es poco entendida.

Palabras clave: influenza, antígeno viral, inmunohistoquímica, estreptavidina-fosfatasa alcalina.

\section{Referencias}

1. Haines D, Waters E, Clark E. Immunohistochemical detection of swine influenza virus in formalin-fixed 
and paraffin-embedded tissues. Can J Vet Res. 1993; 57:33-6.

2. Guarner J, Paddock C, Shieh W, Packard M, Patel M, Montague J, et al. Histopathologic and immunohistochemical features of fatal influenza virus infection in children during the 2003-2004 season. Clin Infect Dis. 2006;43:132-40.

3. Burnett R, Guichard Y, Barale E. Immunohistochemistry for light microscopy in safety evaluation of therapeutic agents: an overview. Toxicology. 1997;119:83-93.

\section{$\overline{\overline{\underline{2}}}$}

\section{Utilidad de IgY e IgG anti-Giardia de aislamientos colombianos para detectar antígeno del parásito en el gerbo}

Adriana Arévalo ${ }^{1}$, Sofía Duque ${ }^{1}$, Rafael Guerrero ${ }^{3}$, Martha Nancy Calderón ${ }^{2}$, Liliana Arias $^{3}$, Daissy Ariza ${ }^{3}$, Rubén Santiago Nicholls ${ }^{1}$

1 Grupo de Parasitología, Subdirección de Investigación, Instituto Nacional de Salud, Bogotá, D.C., Colombia

2 Universidad Nacional de Colombia, Bogotá, D.C., Colombia

3 Universidad Colegio Mayor de Cundinamarca, Bogotá, D.C., Colombia

aarevalo@ins.gov.co

Introducción. Tradicionalmente, el diagnóstico de giardiosis se realiza mediante la visualización del parásito en heces. Sin embargo, existe dificultad en el diagnóstico por la excreción intermitente de Giardia sp., fenómeno inherente a la biología del parásito, que ha sido demostrado en gerbo, modelo animal para estudios de giardiosis.

Objetivo. Evaluar la utilidad de $\lg Y$ e $\lg G$ antiGiardia para detectar antígeno del parásito en heces de gerbo.

Materiales y métodos. Se infectaron gerbos con quistes de Giardia sp. y se recolectaron muestras de heces para la elaboración de coproantígeno, de las cuales se tomaron 46 muestras positivas. Además, se tomaron 46 muestras de gerbos sanos y 13 de gerbos infectados naturalmente con Trichomonas sp. Se purificaron anticuerpos lgG e IgY anti-Giardia por cromatografía de afinidad, y se determinó la actividad biológica mediante contrainmunoelectroforesis y Western blot. Se desarrollólaELISAtiposándwichindirecto, utilizando IgY (primera captura) e IgG (segunda captura). Se evaluaron la sensibilidad, la especificidad, el valor diagnóstico positivo y negativo y el punto de corte mediante la curva de características operativas del receptor.
Resultados. Se establecieron concentraciones óptimas de anticuerpos IgG e IgY anti-Giardia de $10 \mu \mathrm{g} / \mathrm{ml}$ y una dilución 1:1.000 conjugado anti$\operatorname{lgG}$ de conejo unido a fosfatasa alcalina. Todas las muestras con presencia de Giardia sp. fueron positivas en la prueba ELISA con un punto de corte de 0,04 , a partir del cual se estimó una sensibilidad de $100 \%\left(\mathrm{IC}_{95 \%}: 98,9-100\right)$, especificidad de 100 $\%$ (IC $\left.{ }_{95 \%}: 99,2-100\right)$, valor diagnóstico positivo de $100 \%\left(\mathrm{IC}_{95 \%}: 98,9-100\right)$ y negativo de $100 \%\left(\mathrm{IC}_{95 \%}\right.$ : 99,2-100).

Conclusión. La prueba de ELISA con captura $\lg Y$ e IgG anti-Giardia es útil para la detección de antígeno de Giardia sp. en muestras fecales de gerbo. Esto puede afirmarse con exactitud ya que las heces provenían de gerbos infectados con el parásito desde el día cero hasta el día 30 cuando los animales pudieron resolver la infección. Este protocolo puede adaptarse para la evaluación en heces humanas.

Palabras clave: Giardia sp., anticuerpos policlonales, antígeno, ELISA, gerbo.

\section{Referencias}

1. Arévalo A, Duque S, Nicholls RS. Comportamiento de la infección experimental por aislamientos colombianos de Giardia duodenalis en el modelo animal del gerbo (Meriones unguiculatus). Biomédica. 2005;25:305-14.

2. Amorim RM, Silva DA, Taketomi EA, Morato MG, Mundim MJ, Ribeiro DP, et. al. Giardia duodenalis: kinetics of cyst elimination and the systemic humoral and intestinal secretory immune responses in gerbils (Meriones unguiculatus) experimentally infected. Exp Parasitol. 2010;125:297-303.

3. García DA, Nicholls RS, Arévalo A, Torres O, Duque S. Obtención, purificación y caracterización de anticuerpos policlonales $\lg Y$ desarrollados en gallina, dirigidos contra aislamientos colombianos de Giardia duodenalis. Biomédica. 2005;25:451-63.

\section{Detección de antígeno de Giardia sp. en materia fecal humana utilizando IgY e IgG anti-Giardia por el método de ELISA}

Sofía Duque ${ }^{1}$, Adriana Arévalo ${ }^{1}$, Rafael Guerrero², Martha Nancy Calderón ${ }^{2}$, Rubén Santiago Nicholls ${ }^{1}$

${ }^{1}$ Grupo de Parasitología, Subdirección de Investigación, Instituto Nacional de Salud, Bogotá, D.C., Colombia

2 Universidad Nacional de Colombia, Bogotá, D.C., Colombia

sduque@ins.gov.co

Introducción. La giardiosis es una infección intestinal causada por el protozoo Giardia sp. Su alta 
prevalencia se encuentra asociada con situaciones de pobreza, y saneamiento ambiental inadecuado. Usualmente, el diagnóstico se realiza mediante la observación microscópica del parásito en heces. Sin embargo, la sensibilidad de esa prueba con tres muestras aumenta sólo hasta el $85 \%$. Esta dificultad se debe a la excreción intermitente del parásito en heces que es inherente a su biología.

Objetivo. Evaluar la utilidad de $\lg Y$ e $\lg G$ antiGiardia para detectar antígeno del parásito en heces humanas mediante ELISA.

Materiales y métodos. Se evaluaron 131 "eluidos" de materia fecal humana (coproantígeno), 46 con ausencia de Giardia sp., 46 con Giardia sp. y 39 con otros parásitos intestinales, para la detección de antígeno de Giardia sp. mediante ELISA estandarizado en gerbo, utilizando IgY anti-Giardia como primera captura e IgG anti-Giardia como segunda captura, y se purificaron por cromatografía de afinidad. Los parámetros evaluados fueron: sensibilidad, especificidad, valor diagnóstico positivo y negativo, y punto de corte mediante la curva de características operativas del receptor.

Resultados. Todas las muestras con presencia de Giardia sp. fueron identificadas positivas en la prueba de ELISA con punto de corte de 0,04, a partir del cual se estimó una sensibilidad de 100 \% (IC $\left.{ }_{95 \%} 98,91-100\right)$, especificidad de $100 \%\left(\mathrm{IC}_{95 \%}\right.$ $99,41-100)$, valor diagnóstico positivo de $100 \%$ $\left(\mathrm{IC}_{95 \%} 98,91-100\right)$ y negativo de $100 \%\left(\mathrm{IC}_{95 \%} 99,41-\right.$ 100).

Conclusión. Los anticuerpos anti-Giardia del parásito fueron útiles porque garantizaron la identificación de los metabolitos de excreción y secreción presentes en heces.

Esta prueba de ELISA para la detección de antígeno de Giardia sp. muestra un gran potencial para someterla a proceso de evaluación y validación como prueba diagnóstica, y así determinar su utilidad en población general.

Palabras clave: Giardia sp., anticuerpos policlonales, antígeno, ELISA, humanos.

\section{Referencias}

1. Duque $S$, Nicholls RS, Arévalo A, Guerrero R, Montenegro $\mathrm{S}$, James MA. Detection of Giardia duodenalis antigen in human fecal eluates by enzyme-linked immunosorbent assay using polyclonal antibodies. Mem Inst Oswaldo Cruz. 2002;97:1165-8.

2. Fuentes I, Gutiérrez MJ, Gárate T. Diagnóstico de las parasitosisintestinalesmediantedeteccióndecoproantígenos. Enferm Infecc Microbiol Clin. 2010;28(Suppl.1):33-9.
3. Qu JX, Lin $\mathrm{YH}, \mathrm{Ma} \mathrm{RS}$, Wang $\mathrm{H}$. Immunoaffinity purification of polyepitope proteins against Plasmodium falciparum with chicken IgY specific to their C-terminal epitope tag. Protein Expr Purif. 2011;75:225-9.

\section{Validación de la metodología para la determinación de Cryptosporidium sp. y Giardia sp. según método EPA 1623}

Karina Piñeros, Andrés Otálora, Gerardo Nava, Jaime E. Ortiz q.e.p.d.

Grupo de Salud Ambiental, Subdirección Red Nacional de Laboratorios, Instituto Nacional de Salud, Bogotá, D.C., Colombia

gnavat@ins.gov.co

Introducción. El programa de aguas del Grupo de Salud Ambiental, con su laboratorio de microbiología, y teniendo en cuenta la Resolución 2115/07 del Ministerio de la Protección Social, MAVDT, que señala dentro del sistema de control y vigilancia para la calidad del agua para consumo humano, que para la determinación de Giardia sp. y Cryptosporidium sp., las técnicas y metodologías de análisis para estos microorganismos deben ser validadas por el Instituto Nacional de Salud. Se adquirió el equipamiento necesario y se está validando el ensayo de detección de estos parásitos en aguas, según el método EPA 1623.

Objetivo. Realizar la validación secundaria del método EPA 1623 para la determinación de Giardia sp. y Cryptosporidium sp. en agua para consumo humano.

Materiales y métodos. Se empleó el método EPA1623 para la determinación de Giardia sp. y Cryptosporidium sp. en agua para consumo humano.

Resultados. El proceso de validación implica la toma y filtración de muestras, concentración del material, separación inmunomagnética de otros parásitos y confirmación con FITC, DAPI y DIC. Para la validación se han tomado muestras de aguas en cuatro municipios diferentes de Cundinamarca, corridas simultáneamente con muestras fortificadas con material de referencia, para comparar los índices IPR y OPR, cuyos resultados obtenidos muestran recuperaciones por debajo del límite inferior descrito en el método EPA 1623.

Las dificultades para la implementación de la metodología son su costo y el tiempo requerido para el análisis y que, por el momento, sólo hay dos 
empresas que ofrecen la configuración completa; no obstante, para el fortalecimiento de los laboratorios de las autoridades de sanitarias se transferirá la misma, puesto que es una de las características especiales para calcular el índice de riesgo por calidad de agua. Además, se complementará con estudios de brotes de enfermedad diarreica aguda y enfermedades transmitidas por alimentos de posible origen hídrico, garantizando a futuro que la población consuma cada vez agua de mejor calidad en el país.

Conclusión. Hasta el momento se han obtenido índices de recuperación aceptables.
Palabras clave: parasitología, calidad de aguas, validación de métodos, salud pública, salud ambiental.

\section{Referencias}

1. Solarte $Y$, Peña $M$, Madera C. Transmisión de protozoarios patógenos a través del agua para consumo humano. Colombia Médica. 2006;37:74-82.

2. Method 1623: Cryptosporidium and Giardia in water by filtration/IMS/FA. December 2005. Environmental Protection Agency.

3. Vergara CC, Santos NS, Freire SF, Ares ME. La criptosporidiosis en la Región Andina de Colombia: seroprevalencia y reconocimiento de antígenos. Pan Am J Public Health. 2000;8:373-9. 


\section{PRODUCCIÓN}

\section{Descripción de requisitos y etapas para la producción de medios de cultivo}

Giselle Carolina Clavijo, Dorcy Tatiana Díaz

Grupo de Producción y Desarrollo Tecnológico, Área Medios de Cultivo, Subdirección de Producción, Instituto Nacional de Salud, Bogotá, D.C., Colombia dtdiaz@ins.gov.co

Introducción.Losmediosdecultivosonconsiderados una ayuda en el diagnóstico clínico, industrial e investigación de bacterias, hongos y parásitos. Aportan compuestos esenciales que actúan como fuentes de carbono, nitrógeno, minerales y sales, factores de crecimiento (extractos, vitaminas) y en algunos agentes de solidificación (agarosa, gelatina, huevo), permitiendo el crecimiento, aislamiento, identificación, mantenimiento y transporte de diferentes microorganismos. Según su estado físico, los medios de cultivo se clasifican en líquidos, sólidos y semisólidos, y según su composición, en no selectivos, enriquecidos, selectivos y diferenciales.

En el proceso de producción de medios de cultivo, se aplican buenas prácticas de manufactura con personal capacitado, instalaciones, equipos, materiales, reactivos y métodos adecuados.

Objetivo. Ofrecer productos que cumplan con especificaciones técnicas establecidas según normatividad de la Organización Mundial de la Salud, para los diferentes grupos del Instituto Nacional de Salud, como para entidades externas.

Materiales y métodos. Las etapas que describen el proceso son: pesaje de materias primas, hidratación, agitación, ebullición, esterilización, envase, coagulación, identificación del producto terminado y control de calidad.
Según las propiedades físico-químicas de cada medio de cultivo, su método de esterilización puede ser por calor húmedo, filtración o sólo ebullición, y su método de envase depende de la presentación del producto: caja de Petri, tubo o frasco. En el producto terminado, las variables, como atmósfera, temperatura y tiempo, permiten evaluar la recuperación o supervivencia de microorganismos de interés y la inhibición de microorganismos indeseados, y evidenciar reacciones físicas y bioquímicas características del microorganismo.

Conclusión. El uso y aplicación de medios de cultivo sustenta diagnósticos en diferentes ámbitos, permitiendo la validación de técnicas microbiológicas, el uso e innovación de tratamientos antimicrobianos, la evaluación de procesos de limpieza y desinfección, y las pruebas de esterilidad y estabilidad de productos biológicos, entre otros.

Palabras clave: medio de cultivo, microorganismos, proceso, producción, buenas prácticas de manufactura.

\section{Referencias}

1. Buenas prácticas de manufactura. Serie de informes técnicos de la OMS 823. Comité de expertos de la OMS en especificaciones para las preparaciones farmacéuticas, informe 32. Ginebra: Organización Mundial de la Salud.

2. Microbiology of food and animal feeding stuffs. Guidelines on preparation and production of culture media. Part 1: General guidelines on quality assurance for the preparation of culture media in the laboratory ISO/TS 11133-1, 11133-2. First edition; 2000-06-01.

3. Quality control for commercially prepared microbiological culture media; approved standard M22-A3. Third edition. Volume 24, number 19. 